\title{
Millennium time-scale experiments on climate-carbon cycle with doubled $\mathrm{CO}_{2}$ concentration
}

Tomohiro Hajima* (D), Akitomo Yamamoto, Michio Kawamiya, Xuanming Su, Michio Watanabe, Rumi Ohgaito and Hiroaki Tatebe

\begin{abstract}
Earth system models (ESMs) are commonly used for simulating the climate-carbon (C) cycle and for projecting future global warming. While ESMs are most often applied to century-long climate simulations, millennium-long simulations, which have been conducted by other types of models but not by ESM because of the computational cost, can provide basic fundamental properties of climate- $\mathrm{C}$ cycle models and will be required for estimating the carbon dioxide $\left(\mathrm{CO}_{2}\right)$ concentration and subsequent climate stabilization in the future. This study used two ESMs (the Model for Interdisciplinary Research on Climate, the Earth system model version (MIROC-ESM) and the MIROC Earth system version 2 for long-term simulation (MIROC-ES2L)) to investigate millennium-scale climate and C cycle adjustment to external forcing. The $\mathrm{CO}_{2}$ concentration was doubled abruptly at the beginning of the model simulations and kept at that level for the next 1000 or 2000 years; these model simulations were compared with transient simulations where the $\mathrm{CO}_{2}$ was increased at the rate of $1 \%$ year ${ }^{-1}$ for up to 140 years $(1 \mathrm{pctCO} 2)$. Model simulations to separate and evaluate the $\mathrm{C}$ cycle feedbacks were also performed. Unlike the 1pctCO2 experiment, the change in temperature-cumulative anthropogenic $C$ emission $(\triangle T-C E)$ relationship was non-linear over the millennium time-scales; there were differences in this nonlinearity between the two ESMs. The differences in $\Delta T-C E$ among existing models suggest large uncertainty in the $\Delta T$ and $C E$ in the millennium-long climate- $C$ simulations. Ocean $\mathrm{C}$ and heat transport were found to be disconnected over millennium time-scales, leading to longer timescale of ocean $C$ accumulation than heat uptake. Although the experimental design used here was highly idealized, this long-lasting $\mathrm{C}$ uptake by the ocean should be considered as part of the stabilization of $\mathrm{CO}_{2}$ concentration and global warming. Future studies should perform millennium time-scale simulations using a hierarchy of models to clarify climate-C cycle processes and to understand the long-term response of the Earth system to anthropogenic perturbations.
\end{abstract}

Keywords: Global warming, Earth system models, Millennium time-scales, Carbon cycle feedbacks, Transient climate response to cumulative carbon emission, Anthropogenic emission

\footnotetext{
* Correspondence: hajima@jamstec.go.jp

Research Institute for Global Change, Japan Agency for Marine-Earth Science and Technology, 3173-25 Showamachi, Kanazawaku, Yokohama, Kanagawa 236-0001, Japan
} 


\section{Introduction}

It is clear that anthropogenic carbon dioxide $\left(\mathrm{CO}_{2}\right)$ emission via fossil fuel burning and land-use change is the main cause of the current global warming; nations around the world have agreed to make efforts to try to limit global warming well below $2{ }^{\circ} \mathrm{C}$. The global warming induced by anthropogenic $\mathrm{CO}_{2}$ emission involves a series of physical climate and carbon (C) cycle processes-anthropogenically emitted $\mathrm{C}$ is partly absorbed by land and ocean, and the $\mathrm{CO}_{2}$ remaining in the atmosphere has changed the atmospheric radiation balance resulting in radiative forcing, leading to the current warming.

To understand the complex nature of the climate-C cycle systems and to make climate projections, Earth system models (ESMs) have been developed; these models have land and ocean biogeochemical components embedded or overlaid onto physical climate models (e.g., Hajima et al. 2014; Kawamiya et al. 2020). Recent studies using ESMs have revealed that the anthropogenically induced global warming can be well explained by the cumulative anthropogenic $\mathrm{CO}_{2}$ emission; global warming is almost linear in relation to the cumulative amount of anthropogenic $\mathrm{C}$ emission regardless of the choice of future emission scenario (Allen et al. 2009; Matthews et al. 2009; Gillett et al. 2013). The ratio of global warming to cumulative $\mathrm{C}$ emission is called transient climate response to cumulative $\mathrm{CO}_{2}$ emission (TCRE), usually evaluated at the time when the total emission reaches $1000 \mathrm{PgC}$. This relationship between global warming and anthropogenic $\mathrm{CO}_{2}$ emission helps to estimate the $\mathrm{C}$ budget required to not exceed a specific warming target, like the $2^{\circ} \mathrm{C}$ target promised in the Paris agreement (United Nations 2015).

Although the findings on TCRE have provided clear perspective on future cumulative emissions and global warming, the near constancy of TCRE irrespective of scenario choice holds in limited conditions. For example, Stocker et al. (2013) suggested that the constant TCRE is valid for cumulative emissions up to about $2000 \mathrm{GtC}$ and until temperatures peak. After that, the characteristics of TCRE have been intensively examined: for example, MacDougall (2017) suggested that there likely exists a limited range for anthropogenic emissions to result in TCRE being independent of scenario choice; Tachiiri et al. (2019) examined TCRE in various types of idealized scenarios and confirmed that TCRE is stable under scenarios of increasing or stable $\mathrm{CO}_{2}$ concentration. Another example of the typical condition that has not been well examined is the period after net zero anthropogenic emission is achieved. Although Rogelj et al. (2018) assumes, in the calculation of the total amount of $\mathrm{CO}_{2}$ that can be emitted to not exceed a specific warming target "remaining carbon budget", that the temperature change after zero emission (the temperature change is called "zero-emission commitment", ZEC) would be almost zero, it has not been systematically examined how models project the ZEC (Jones et al. 2019; MacDougall et al. 2020).

Another condition that should be further examined and the main purpose of this study is the long-term response of the climate- $\mathrm{C}$ cycle to anthropogenic perturbation. In particular, the long-term stabilization of greenhouse gases and the subsequent climate stabilization correspond to the framework of the United Nations Framework Convention on Climate Change (UN 1992). In addition, the final goal of our attempts in relation to the Paris agreement, beyond the urgent necessity to curb anthropogenic emissions to avoid exceeding a specific warming target, should be the eventual climate stabilization and concentration stabilization of greenhouse gases at a certain level. The eventual stabilization of $\mathrm{CO}_{2}$ concentration can be realized by reducing anthropogenic emissions to the same level as the total natural $\mathrm{C}$ sink or by net zero emission of anthropogenic $\mathrm{C}$ (in this case, the $\mathrm{CO}_{2}$ concentration would slowly decline over hundreds or thousands of years and then the stabilization of concentration and global temperature will be eventually realized (Eby et al. 2009; MacDougall et al. 2020)). In both cases, the climate-C system continues to change for a long time to adjust to the new external forcing, likely from century to millennium time-scale (Archer et al. 2009; Li et al. 2013; Frölicher et al. 2013; Joos et al. 2013; Yamamoto et al. 2018; Rugenstein et al. 2019).

In the physical climate science field, the degree of eventual warming and the time period necessary to reach a new equilibrium state have been intensively examined in the context of "equilibrium climate sensitivity (ECS)". ECS is defined as the eventual warming after doubling of the $\mathrm{CO}_{2}$ concentration from the pre-industrial state and is usually evaluated by applying regression analysis to climate model simulations of 150 years to reduce the computational cost of performing simulations over thousands of years (Gregory et al. 2004; Andrews et al. 2012). To accurately estimate ECS, recent studies actually performed simulations of running climate models over thousands of years until they reach the new equilibrium state (e.g., Danabasoglu and Gent 2009; Li et al. 2013; Paynter et al. 2018; Saint-Martin et al. 2019; Mauritsen et al. 2019), and a multi-model comparison study was conducted by Rugenstein et al. (2019).

When compared with physical climate research, there are few studies that examine how long the $\mathrm{C}$ cycle continues to change in response to external forcing and how much anthropogenic $\mathrm{C}$ eventually accumulates on land and in the ocean on the millennium time-scale. In particular, the feedback strength of $\mathrm{C}$ cycle processes has been examined in century-scale simulations where 
the $\mathrm{CO}_{2}$ concentration is gradually increased by $1 \%$ year $^{-1}$, and thus the feedback strengths have been evaluated as the transient $\mathrm{C}$ cycle response against changing magnitude of external forcing. In addition to such century-scale simulations, the quantification of $\mathrm{C}$ cycle processes in millennium time-scale simulations, as in the experiments for evaluating ECS, will provide perspective on our long-term climate and $\mathrm{CO}_{2}$ concentration stabilization. Although the long-term simulations beyond centuries and the analysis on climate- $\mathrm{C}$ cycle processes have been performed by ESMs of Intermediate Complexity (EMICs) (e.g., Archer et al. 2009; Eby et al. 2013; Zickfeld et al. 2013; Joos et al. 2013), there are few ESM-based studies on the climate-C cycle because of the computational costs (e.g., Frölicher et al. 2013; Joos et al. 2013). Such millennium time-scale experiments by ESMs will reveal the detailed processes on how climate$\mathrm{C}$ cycle processes continue to change toward a new equilibrium state and can provide fundamental understanding on our long-term climate and $\mathrm{CO}_{2}$ concentration stabilization.

In this study, we performed millennium time-scale experiments using ESMs to investigate long-term climate and $\mathrm{C}$ cycle adjustment to external forcing. As in the evaluation of ECS, the $\mathrm{C}$ cycle process was quantified based on experiments where $\mathrm{CO}_{2}$ concentration was abruptly doubled and kept at that level over 1000 or 2000 years, using two ESMs. By using the simulation results, the relationship between global warming and $\mathrm{cu}-$ mulative anthropogenic $\mathrm{C}$ emission can be analyzed. The models and experimental configurations are described in the "Methods" section, and the simulation results are shown in the "Results and discussion" section. We first compare the simulation results of global temperature, ocean, and land $\mathrm{C}$ amount, and diagnosed fossil fuel emission, and then the simulation results are analyzed in terms of global warming and cumulative anthropogenic $\mathrm{C}$ emission, by comparing with that of transient simulations where the $\mathrm{CO}_{2}$ concentration was increased at the rate of $1 \%$ year $^{-1}$. Such analysis is also applied to existing simulation results performed by EMICs. To explore the mechanisms that produce different patterns between the two types of experiments, ocean heat and $C$ uptakes are analyzed together with the discussion on the limitation of near constancy of TCRE. Finally, the summary and conclusions are described in the corresponding sections.

\section{Methods}

\section{Earth system models}

To examine the long-term climate-C cycle response to external forcing, we used two types of ESMs based on Atmosphere-Ocean General Circulation Models (AOGCM): the Model for Interdisciplinary Research on
Climate, the Earth system model version (MIROC-ESM) developed by Watanabe et al. (2011) and the MIROC Earth system version 2 for long-term simulation (MIROC-ES2L), developed by Hajima et al. (2020). The former is a model that was intensively used for the Coupled Model Intercomparison Project phase 5 (CMIP5, Taylor et al. 2012). This model is based on MIROC3.2 coupled with a land C cycle model, a spatially explicit individual-based dynamic global vegetation model (SEIB-DGVM; Sato et al. 2007) and an ocean biogeochemical component including ocean $\mathrm{C}$ cycle model and nutrient-phytoplankton-zooplankton-detritus type ocean ecosystem model. The atmospheric grid system employs a T42 horizontal grid with 80 vertical layers, and the ocean has a grid system that consists of longitudinal spacing of about $1.4^{\circ}$ and latitudinal grid intervals that gradually become finer close to the equator, with 44 levels of vertical coordinates. The latter model, MIROC-ES2L, is the latest generation of MIROC-based ESM and is expected to be intensively used for CMIP6 (Eyring et al. 2016). The physical core is MIROC5.2, and the horizontal resolution of the atmosphere is the same as that of MIROC-ESM but with reduced vertical layers (40; up to $3 \mathrm{hPa}$ ). The ocean grid has the longitudinal grid spacing of $1^{\circ}$, and the meridional grid spacing varies from about $0.5^{\circ}$ near the Equator to $1^{\circ}$ in the midlatitudes. This model has a land biogeochemical component model, the Vegetation Integrative Simulator for Trace gases model (VISIT; Ito and Inatomi 2012), extended for the ESM and embeds an updated ocean biogeochemical component named OECO2 (Hajima et al. 2020).

\section{Simulations}

Using the two ESMs, we performed several types of millennium time-scale experiments in addition to other experiments performed in CMIP (Table 1). The first was a control run "CTL", where external forcing like $\mathrm{CO}_{2}$ concentration was fixed at pre-industrial levels. The control run was performed over 2000 years by MIROC-ESM and 1000 years by MIROC-ES2L. These experiments were originally performed for CMIP5/CMIP6 experiments, but in this study, the simulations were extended up to 1000 and 2000 years.

The second type of experiment was the "FULL ${ }^{2} \times \mathrm{CO} 2$ " experiment, where the atmospheric $\mathrm{CO}_{2}$ concentration was abruptly doubled (hereafter presented by " $2 \times$ $\mathrm{CO} 2$ ") and held at that level during the same period as in the CTL runs. These experiments were similar to an idealized experiment of CMIP5/CMIP6, where the $\mathrm{CO}_{2}$ concentration abruptly quadrupled over a few centuries, but in this study, the simulation period was extended to 1000 or 2000 years, and the $\mathrm{CO}_{2}$ concentration was doubled, not quadrupled. 
Table 1 Models, experimental configurations, and time periods of simulation used in this study

\begin{tabular}{|c|c|c|c|c|c|}
\hline Experiment name & CTL & $\mathrm{FULL}^{2 \times \mathrm{CO} 2}$ & $\mathrm{BGC}^{2} \times \mathrm{CO} 2$ & $\mathrm{RAD}^{2 \times \mathrm{CO} 2}$ & $1 \mathrm{pctCO} 2$ \\
\hline Experimental configuration on $\mathrm{CO}_{2}$ concentration & Fix at pre-industrial level & \multicolumn{3}{|c|}{ Abruptly doubled and fixed } & Increased by $1 \%$ year $^{-1}$ \\
\hline Simulation years: MIROC-ESM & 2000 years & 2000 years & 2000 years & 2000 years & 140 years \\
\hline Simulation years: MIROC-ES2L & 1000 years & 1000 years & _- & - & 140 years \\
\hline
\end{tabular}

The third and fourth experiments, named "BGC" $\times$ $\mathrm{CO} 2$ " and " $\mathrm{RAD}^{2} \times \mathrm{CO} 2$ ", respectively, were special simulations to evaluate the $\mathrm{C}$ cycle feedbacks. These two experiments were performed by MIROC-ESM only. The former experiment was designed to isolate the $\mathrm{C}$ cycle change in response to $\mathrm{CO}_{2}$ increase. In this experiment, $\mathrm{CO}_{2}$ concentration change was only detected by $\mathrm{C}$ cycle processes, and the atmospheric radiation process was maintained at the pre-industrial level concentration. Thus, in the $\mathrm{BGC}^{2} \times \mathrm{CO}^{2}$ experiment, there was no global warming induced by $\mathrm{CO}_{2}$ concentration increase, and direct stimulation of $\mathrm{CO}_{2}$ increase was the main driver of $\mathrm{C}$ cycle change. The $\mathrm{RAD}^{2} \times \mathrm{CO}^{2}$ experiment, in contrast, was designed to evaluate the $\mathrm{C}$ cycle change solely in response to climate change. In this experiment, the atmospheric radiation process detected the $\mathrm{CO}_{2}$ increase, but there was no direct stimulation of $\mathrm{CO}_{2}$ increase on land and ocean $\mathrm{C}$ cycle processes. Thus, climate change was the main driver of $\mathrm{C}$ cycle change in this experiment. These two types of experiments were originally devised in the multi-model comparison on climate- $\mathrm{C}$ cycle models in the Coupled Carbon Cycle Climate Model Intercomparison Project (C4MIP, Arora et al. 2013; Jones et al. 2016), but the $\mathrm{CO}_{2}$ concentration in the original C4MIP experiment was increased by $1 \%$ year $^{-1}$ over 140 years (named "1pctCO2").

Finally, to analyze the relationship between global temperature change and cumulative anthropogenic $\mathrm{C}$ emission, the $1 \mathrm{pctCO} 2$ simulation results from MIROC-ESM and MIROC-ES2L were also compared with the millennium time-scale experiment. The $1 \mathrm{pctCO} 2$ experiments were performed as one of the experiments of CMIP5/ CMIP6 and already reported in several places (e.g., Hajima et al. 2012; Gillett et al. 2013; Hajima et al. 2020).

All experiments performed in this study were based on prescribed $\mathrm{CO}_{2}$ concentration, and thus the anthropogenic $\mathrm{C}$ emissions were diagnosed from the prescribed $\mathrm{CO}_{2}$ concentration and simulated $\mathrm{C}$ uptake by land and ocean, as shown below:

$$
E=\mathrm{d} C_{\mathrm{A}} / \mathrm{dt}+\mathrm{d} C_{\mathrm{L}} / \mathrm{dt}+\mathrm{d} C_{\mathrm{O}} / \mathrm{dt}
$$

where $E$ is the annual anthropogenic emission; $C_{\mathrm{A}}, C_{\mathrm{L}}$, and $C_{\mathrm{O}}$ are changes in the $\mathrm{C}$ amount in the atmosphere, land, and ocean, respectively; and the time derivatives of the land and ocean $\mathrm{C}$ amounts corresponded to their net C uptake.

\section{Simulations by EMICs}

When compared with ESMs, EMICs have less complexity of climate- $\mathrm{C}$ cycle processes in some component models, and thus the models can effectively be run over millennium time-scales. Eby et al. (2013) and Zickfeld et al. (2013) performed various types of long-term simulations using multiple EMICs (named "EMIC-AR5"), and we obtained the simulation results from eight of the EMICs (Bern3D, DCESS, GENIE, IGSM, MESMO, MIROC3-lite-LCM, UMD, and UVic ESCM) for 1 pctCO2 (140 years) and FULL ${ }^{2} \times \mathrm{CO}^{2}$ (1000 years) experiments. The results of global temperature and $\mathrm{C}$ fluxes were compared with those of MIROC-ESM and MIROC-ES2L simulations.

\section{Results and discussion}

\section{Global changes in temperature and C storages}

The results of global mean surface air temperature change $(\Delta \mathrm{T})$ and changes in land and ocean $\mathrm{C}$ amount are shown in Fig. 1 and Table 2, after removing the trends that were found in CTL (the successful removal of the trends can be confirmed in the gray lines in Fig. 1, and the result before the detrending operation is shown in Fig. S1). In the $\mathrm{FULL}^{2 \times \mathrm{CO} 2}$ experiment by MIROCESM, there was a temperature increase of about $3{ }^{\circ} \mathrm{C}$ in the first few centuries. Then, slight warming started at around 600-700 years, and in the latter half of the simulation, $\Delta \mathrm{T}$ was almost stabilized and finally reached $3.2{ }^{\circ} \mathrm{C}$ above the warming when compared with CTL. This number is much smaller than the ECS estimates of $4.7^{\circ} \mathrm{C}$ by Andrews et al. (2012), in which linear regression analyses using 150 year simulations, the so called "Gregory method," were used for the ECS evaluation. One of the likely reasons for the ECS discrepancy between the actual warming in $\mathrm{FULL}^{2 \times \mathrm{CO} 2}$ and the result of Andrews et al. (2012) is the strong and non-linear warming trend found in the CTL experiment by MIROC-ESM (Fig. S1); although Andrews et al. (2012) considers such global temperature drift in the control run, the analysis relies on 150 year simulation results, which might be insufficient to capture the strong and non-linear drift of MIROC-ESM. Additionally, similar to the MIROC-ESM result, Li et al. (2013) also suggested an overestimation of ECS by the linear regression method; their 6000 year simulation using a climate model also showed smaller global warming than the ECS estimated by the Gregory method. Throughout the 


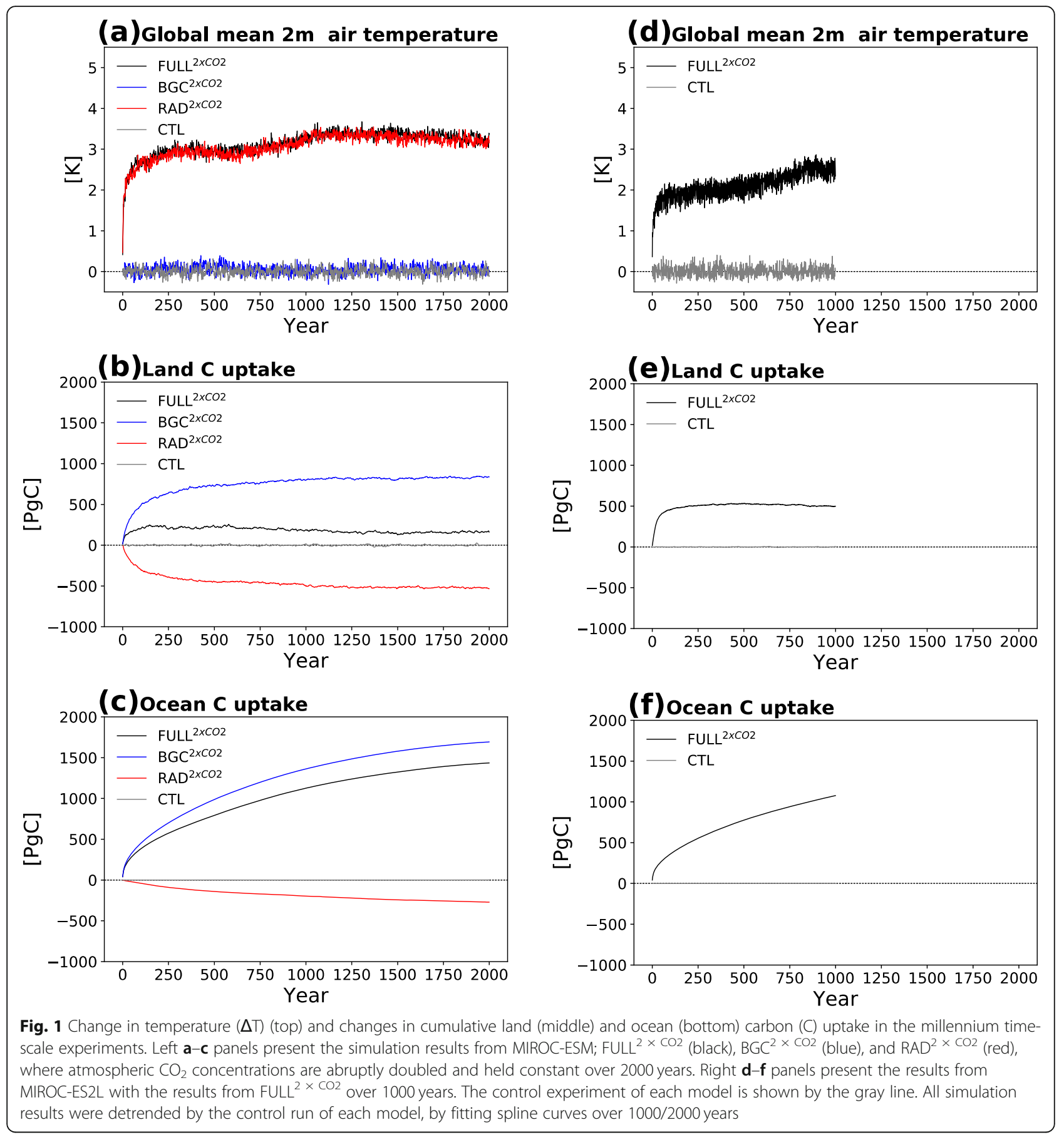

simulation period, most of the global warming was realized in the first half of the 2000 year simulation. As expected from the experimental designs, $\Delta \mathrm{T}$ in $\mathrm{BGC}^{2} \times$ $\mathrm{CO}_{2}$ was almost constant and very close to zero because abrupt $\mathrm{CO}_{2}$ doubling does not affect atmospheric radiative processes; $\triangle \mathrm{T}$ in the $\mathrm{RAD}^{2} \times \mathrm{CO}^{2}$ experiment almost overlapped with that of $\mathrm{FULL}^{2 \times \mathrm{CO} 2}$.

In the $\mathrm{FULL}^{2} \times \mathrm{CO}^{2}$ experiment by MIROC-ESM, land showed quite a small change in $\mathrm{C}$ amount. Although atmospheric $\mathrm{CO}_{2}$ increase actually stimulates land ecosystems (Fig. 1b, results from $\mathrm{BGC}^{2} \times \mathrm{CO}^{2}$ experiment shown by the blue line), most of this land $C$ sink induced by $\mathrm{CO}_{2}$ stimulation was opposed by the large $\mathrm{C}$ loss that was induced by global warming and the resultant increase in ecosystem respiration (confirmed by the results of the $\mathrm{RAD}^{2 \times \mathrm{CO}^{2}}$ experiment shown by the red line in the panel). This weak land C sink in the FULL ${ }^{2 \times}$ $\mathrm{CO} 2$ experiment is consistent with the results of the 
Table 2 The simulation results of FULL $2 \times \mathrm{CO}^{2}, \mathrm{BGC}^{2} \times \mathrm{CO} 2$, and $\mathrm{RAD}^{2} \times \mathrm{CO}^{2}$ by MIROC-ESM and MIROC-ES2L

\begin{tabular}{|c|c|c|c|c|c|c|c|c|c|}
\hline & & \multicolumn{4}{|c|}{ 1000th year } & \multicolumn{4}{|c|}{ 2000th year } \\
\hline & & $\Delta \mathrm{T}^{*}[\mathrm{~K}]$ & $\mathrm{CL}^{+}[\mathrm{PgC}]$ & $\mathrm{CO}^{\ddagger}[\mathrm{PgC}]$ & $\overline{C E^{\S}[\mathrm{PgC}]}$ & $\overline{\Delta T^{*}[K]}$ & $\mathrm{CL}^{+}[\mathrm{PgC}]$ & $\mathrm{CO}^{\ddagger}[\mathrm{PgC}]$ & $\overline{C E^{\S}[\mathrm{PgC}]}$ \\
\hline \multirow[t]{3}{*}{ MIROC-ESM } & $\mathrm{FULL}^{2 \times \mathrm{CO} 2}$ & 3.2 & 180 & 1121 & 1904 & 3.2 & 167 & 1435 & 2205 \\
\hline & $\mathrm{BGC}^{2 \times \mathrm{CO} 2}$ & 0.1 & 800 & 1357 & 2761 & 0.0 & 836 & 1691 & 3131 \\
\hline & $\mathrm{RAD}^{2 \times \mathrm{CO} 2}$ & 3.3 & -487 & -196 & -79 & 3.2 & -527 & -272 & -195 \\
\hline MIROC-ES2L & $\mathrm{FULL}^{2} \times \mathrm{CO}^{2}$ & 2.5 & 497 & 1072 & 2172 & - & - & - & - \\
\hline
\end{tabular}

The values presented are 20 year averages (e.g., the average of years $981-1000$ is used for the value of year 1000). All results are calculated after the detrending as in Fig. 1. Please refer to Table 1 for descriptions of models, model configurations, and time periods of simulations

${ }^{*} \Delta T$, Global mean surface air temperature change

$+\mathrm{CL}$, Cumulative land carbon $(\mathrm{C})$ uptake

$\neq \mathrm{CO}$, Cumulative ocean $\mathrm{C}$ uptake

$\S C E$, Cumulative anthropogenic $C$ emission

1pctCO2 experiment (Arora et al. 2013). The C amount in vegetation and soil kept changing beyond 1000 years (Fig. S2) because (1) the vegetation $C$ kept increasing because of the spatial redistribution of vegetation (e.g., the boreal forest invasion into the tundra region) and (2) soil $\mathrm{C}$ kept declining in the northern hemisphere high latitude areas because of the lag in response behind climate change. In contrast, the ocean component showed a strong and long-lasting $\mathrm{C}$ sink (black line in Fig. 1c), which was mainly caused by $\mathrm{CO}_{2}$ stimulation of ocean biogeochemistry (blue line in the panel). Although the ocean $\mathrm{C}$ sink was somewhat reduced by the global warming effect (red line), the $\mathrm{C}$ reduction induced by global warming was smaller than that of land, as confirmed in a previous study (Arora et al. 2013). When compared with land, the ocean continued to accumulate C throughout the simulation period, although the rate of increase gradually declined.

The $\Delta \mathrm{T}$ in MIROC-ES2L was relatively small compared with that in MIROC-ESM, and the $\Delta \mathrm{T}$ after 1000 years was about $2.5^{\circ} \mathrm{C}$ (Fig. 1d; Table 2). This reduced warming in MIROC-ES2L as opposed to MIROC-ESM was already confirmed by comparing the transient climate response in each model (Hajima et al. 2020: MIROC-ESM is $2.2 \mathrm{~K}$ while MIROC-ES2L is $1.5 \mathrm{~K}$ ), and by comparing ECSs based on the Gregory method (4.7 K for MIROC-ESM by Andrews et al. 2012 and $2.7 \mathrm{~K}$ for MIROC-ES2L by Tsutsui 2020). When compared with MIROC-ESM, MIROC-ES2L shows a stronger land C sink of about $500 \mathrm{PgC}$ accumulation (Fig. 1e; Table 2), by increasing the $\mathrm{CO}_{2}$-induced $\mathrm{C}$ accumulation and reducing warming-induced $\mathrm{C}$ loss (Hajima et al. 2020). Although the global land $\mathrm{C}$ change almost ceased within a few hundred years, regional soil $\mathrm{C}$ change was still present at around year 1000, and soil C reduction in boreal forest and in other warmer regions was partly compensated by the soil $\mathrm{C}$ accumulation in the tundra region. The ocean $\mathrm{C}$ sink in MIROC-ES2L was slightly smaller than that of MIROC-ESM at year 1000 (Fig. 1f; Table 2), as expected from the almost unchanged strength of $\mathrm{C}$ cycle feedback of the ocean in the two models (Hajima et al. 2020). As in MIROC-ESM, the ocean in MIROC-ES2L continued to show $\mathrm{C}$ accumulation over the 1000 year period while the land $C$ was almost stabilized within a few centuries. We note that although MIROC-ES2L explicitly simulates the $\mathrm{C}$ removal by the ocean sedimentation process of about 0.07 $\mathrm{PgC}$ year $^{-1}$ (this can be confirmed by the linear ocean C uptake found in CTL, Fig. S1), the contribution of the sedimentation process to ocean $\mathrm{C}$ change is excluded in Fig. 1 and in other results displayed herein.

\section{Diagnosed annual anthropogenic emission}

The annual mean anthropogenic $\mathrm{C}$ emissions diagnosed from the $\mathrm{FULL}^{2} \times \mathrm{CO} 2$ simulation by two models are shown in Fig. 2 (and the cumulative anthropogenic $\mathrm{C}$ emissions are shown in Fig. S2). To maintain consistency with the abrupt $\mathrm{CO}_{2}$ concentration doubling, more than $500 \mathrm{PgC}$ year $^{-1}$ emission should be added to the atmosphere in the first year of the simulation. In addition, because the land and the ocean start to accumulate $\mathrm{C}$ in response to the abrupt $\mathrm{CO}_{2}$ concentration increase, the total annual emissions in the first year exceeded $600 \mathrm{PgC}$ (Fig. $2 \mathrm{a}$ and $\mathrm{f}$ ) in both models.

After the second year, because the $\mathrm{CO}_{2}$ concentration was fixed at $2 \times \mathrm{CO}_{2}$ level, there should be no change in the atmospheric $\mathrm{C}$ concentration. Thus, the annual compatible emission should be identical to the sum of the $\mathrm{C}$ changes in land and ocean hereafter. In the first decades, the annual emissions were more than $10 \mathrm{PgC}_{\text {year }}{ }^{-1}$, but the emission rates gradually reduced. Contributions from land and ocean to the annual emission were almost comparable, but the contribution from land was different between the two models-MIROC-ES2L showed larger land contribution than MIROC-ESM because of the intensified land $\mathrm{C}$ sink, as mentioned above. After 50 years, although both the natural $\mathrm{C}$ sink of land and ocean resulted in anthropogenic emissions exceeding 2 PgC year ${ }^{-1}$ (Fig. $2 \mathrm{~d}$ and i), the land contribution gradually reduced and almost vanished after 250 years; MIROC-ESM showed a slight negative contribution of land to anthropogenic emissions over this time-scale. 

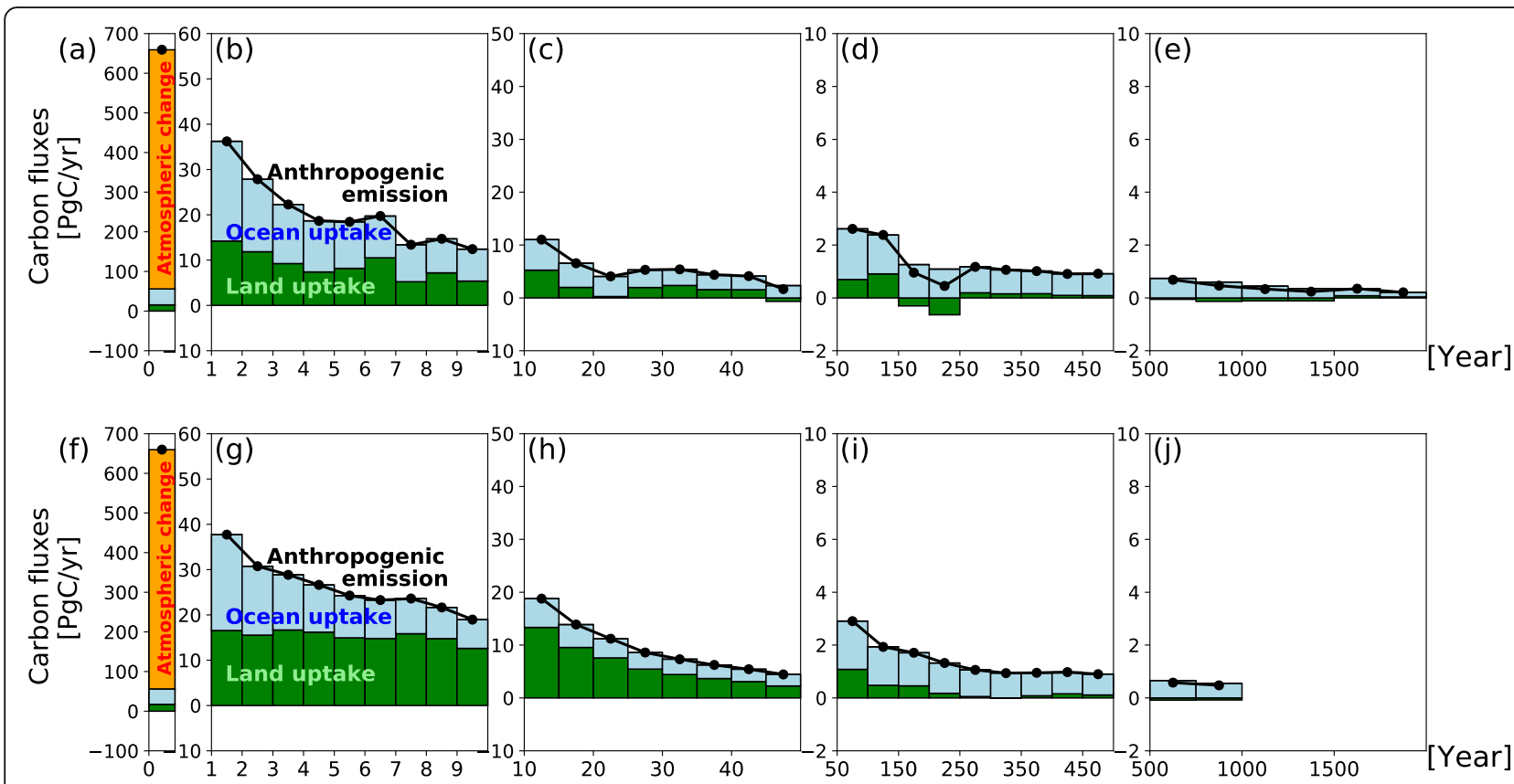

Fig. 2 Changes in atmospheric carbon (C) pool, annual land/ocean C uptake, and diagnosed anthropogenic emission in the FULL ${ }^{2} \times \mathrm{CO}_{2}$ experiments: the 2000 years simulation by MIROC-ESM (top) and the 1000 years simulation by MIROC-ES2L (bottom). The annual C emission is diagnosed as the sum of $\mathrm{C}$ changes in the atmosphere, land, and the ocean, and presented in the figure as black dotted lines. Color bars represent changes in C storages of atmosphere (orange) and annual C uptake by ocean (light blue) and land (green). In panels $\mathbf{c}$ and $\mathbf{h}, \mathbf{d}$ and $\mathbf{i}$, and $\mathbf{e}$ and $\mathbf{j}$, the annual $\mathbf{C}$ fluxes were calculated as the averages of 5-, 25-, and 250 year intervals, respectively

Even after 1000 years have passed, both models projected positive anthropogenic emission originating from the ocean $\mathrm{C}$ uptake, but the emission rates were less than $1 \mathrm{PgC}$ year $^{-1}$. The slight $C$ uptake by the ocean was maintained even after 2000 years, as simulated by MIROC-ESM.

\section{Relationship between global temperature rise and cumulative emission}

To understand the relationship between global warming and anthropogenic emission on the millennium timescale, $\Delta \mathrm{T}$ and cumulative anthropogenic $\mathrm{C}$ emission (CE) in the experiments were examined (Fig. 3; Table 2). The $\Delta \mathrm{T}-\mathrm{CE}$ relationship is well-known to be almost linear in simulations of $1 \mathrm{pctCO} 2$ or historical to future climate projections (Allen et al. 2009; Matthews et al. 2009; Gillett et al. 2013), and this was also confirmed in the 1 pctCO2 experiments by the two models (green dots, Fig. 3). In the FULL ${ }^{2 \times \mathrm{CO} 2}$ experiment, because atmospheric $\mathrm{CO}_{2}$ concentration is instantaneously doubled in the first year, the $\Delta \mathrm{T}-\mathrm{CE}$ plots do not start from the origin of the plot (black dots, Fig. 3). As CE increased, $\Delta \mathrm{T}$ in $\mathrm{FULL}^{2} \times \mathrm{CO}^{2}$ by the two models showed an almost linear increase, overlapping the result on the plot for 1 pctCO2. However, after 400 years, the global temperature in the FULL ${ }^{2 \times \mathrm{CO} 2}$ experiment by MIROCESM was almost stabilized at around $3{ }^{\circ} \mathrm{C}$ while the $\mathrm{CE}$ continued to increase. As a result, the $\triangle \mathrm{T}-\mathrm{CE}$ plot of $\mathrm{FULL}^{2 \times \mathrm{CO} 2}$ started to deviate from that of the $1 \mathrm{pctCO} 2$ experiment at around year 400, and this deviation was more clearly recognized in MIROC-ESM than in MIROC-ES2L. As mentioned above, at around 600-700 years the two models showed a slight increase in $\Delta \mathrm{T}$ (Fig. 1), and this slight warming was confirmed in the $\triangle \mathrm{T}-\mathrm{CE}$ plot (Fig. 3).

The $\mathrm{BGC}^{2} \times \mathrm{CO}^{2}$ and $\mathrm{RAD}^{2} \times \mathrm{CO}^{2}$ simulation results from MIROC-ESM are also presented in Fig. 3 (blue and red dots, respectively). In the $\mathrm{BGC}^{2 \times \mathrm{CO} 2}$ experiment, because the $\mathrm{CO}_{2}$ increase only stimulates the $\mathrm{C}$ cycle without $\mathrm{CO}_{2}$-induced global warming, the $\triangle \mathrm{T}-\mathrm{CE}$ plot lies on the horizontal axis, showing $\mathrm{CE}$ exceeding $3000 \mathrm{PgC}$. In the $\mathrm{RAD}^{2} \times \mathrm{CO} 2$ experiment, because the $\mathrm{CO}_{2}$ increase does not stimulate the $\mathrm{C}$ cycle but perturbs the atmospheric radiation balance, $\mathrm{CO}_{2}$-induced global warming occurs as in the $\mathrm{FULL}^{2} \times \mathrm{CO}^{2}$ experiment. This global warming reduced the $\mathrm{CE}$ in the $\mathrm{RAD}^{2} \times \mathrm{CO} 2$ experiment to $-195 \mathrm{PgC}$. The synthesis of the final condition of the $\mathrm{BGC}^{2 \times \mathrm{CO} 2}$ and $\mathrm{RAD}^{2 \times \mathrm{CO} 2}$ simulations (blue circle filled by red in Fig. 3) is close to the final condition of the FULL $^{2} \times \mathrm{CO}^{2}$ experiment (black circle), although there is a mismatch between the $\mathrm{FULL}^{2 \times \mathrm{CO} 2}$ and $\mathrm{BGC}^{2 \times \mathrm{CO} 2}$ plus $\mathrm{RAD}^{2} \times \mathrm{CO}^{2}$ in terms of CE. In summary, if the $\mathrm{CO}_{2}$ concentration was doubled without producing radiative forcing, there would be a total C emission of about $3100 \mathrm{PgC}$ 


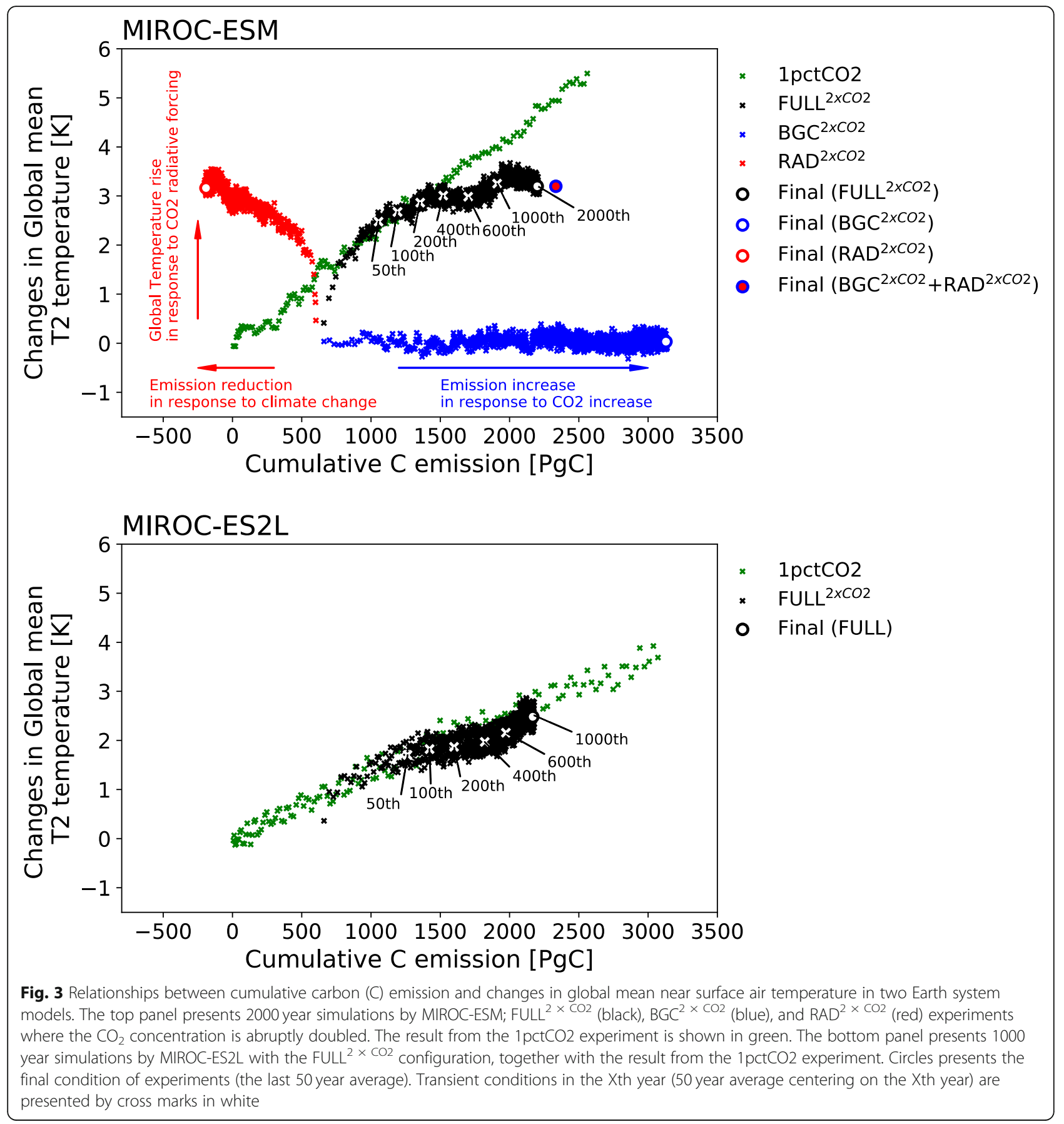

by the $\mathrm{C}$ cycle response to $\mathrm{CO}_{2}$ increase, but this cumulative $\mathrm{C}$ emission should be reduced by about $900 \mathrm{PgC}$ because of the warming effect on natural $\mathrm{C}$ uptake, leading to the cumulative emission of about $2200 \mathrm{PgC}$ in the $\mathrm{FULL}^{2 \times \mathrm{CO} 2}$ experiment (Table 2).

\section{Quantifying the dissimilarity of $\Delta T$ and CE relationship} between 1 pctCO2 and FULL experiments

In the sections above, we confirmed that the $\Delta \mathrm{T}-\mathrm{CE}$ relationship in the $\mathrm{FULL}^{2} \times \mathrm{CO}^{2}$ experiments was not linear, unlike the case of $1 \mathrm{pctCO}$, and that this nonlinearity was more evident in MIROC-ESM than MIROCES2L-the degree of nonlinearity of the $\triangle \mathrm{T}-\mathrm{CE}$ relationship in $\mathrm{FULL}^{2} \times \mathrm{CO} 2$ was different between the two models. MIROC-ESM showed strong nonlinearity, which was illustrated as a large deviation of the $\mathrm{FULL}^{2} \times \mathrm{CO}^{2}$ experiment from 1 pctCO2 in the latter period of the 2000 year simulation (top panel of Fig. 3). In contrast, MIROC-ES2L showed limited nonlinearity in the FULL ${ }^{2}$ $\times \mathrm{CO}^{2}$ experiment, with close positioning of the $\mathrm{FULL}^{2} \times$ 
$\mathrm{CO} 2$ result in relation to that of 1 pctCO2 (bottom panel of Fig. 3). To quantitatively discuss the difference between the models, we first define several quantities for evaluating temperature, $\mathrm{C}$, and temperature- $\mathrm{C}$, as summarized in Fig. 4.

For discussing global temperature change in models, some quantities have been conventionally utilized in the climate science field: transient climate response (TCR), equilibrium climate sensitivity (ECS), and unrealized warming (presented here as " $\Delta \mathrm{T}^{\mathrm{UNR}}$ "). $T C R$ is defined as the global temperature rise when the $\mathrm{CO}_{2}$ concentration reaches the $2 \times \mathrm{CO} 2$ level in the 1 pctCO2 experiment. ECS is an equilibrium temperature rise: this can be realized by providing abruptly doubled $\mathrm{CO}_{2}$ concentration to models and running models over thousands of years until they reach a new steady state; in many cases, the ECS values in models are usually estimated by a linear regression method, as mentioned above. As suggested by previous studies, $>2000$ years and up to 10,000 years of simulation will be necessary to obtain the real equilibrium state (e.g., Li et al. 2013). Indeed, the global temperatures at the end of the simulations in this study still have some variations or trends, and thus, we define the global temperature rise at the time of year 1000 as a quasi-ECS "qECS". The unrealized warming, $\Delta \mathrm{T}^{\mathrm{UNR}}$, is usually defined as the difference between ECS and TCR. However, since we cannot obtain a real ECS, we thus define $\Delta \mathrm{T}^{\mathrm{UNR}}$ as $\mathrm{qECS}-\mathrm{TCR}$.

Similarly, we define C-related quantities for quantifying the $\triangle \mathrm{T}-\mathrm{CE}$ relationship in experiments: transient cumulative emission (TCE), quasi-equilibrium cumulative emission (qECE), unrealized $C$ uptake $\left(\Delta C^{\mathrm{UNR}}\right)$, and additional $C$ uptake $\left(\Delta C^{\mathrm{ADD}}\right)$. Analogous to TCR, TCE is defined here as the cumulative $\mathrm{C}$ emission when $\mathrm{CO}_{2}$ reaches $2 \times \mathrm{CO}_{2}$ level in the 1 pctCO2 experiment (if the cumulative airborne fraction of emitted carbon (AF, defined as $\mathrm{CA} / \mathrm{CE}$ ) of $1 \mathrm{pctCO} 2$ in existing models is available, TCE can be estimated by: $\mathrm{TCE}=\mathrm{CA}^{2} \times \mathrm{CO}^{2} / \mathrm{AF}$, where $\mathrm{CA}^{2} \times \mathrm{CO}^{2}$ is the atmospheric carbon change at the doubled $\mathrm{CO}_{2}$ concentration level). qECE is defined as the cumulative emission of year 1000 of the $\mathrm{FULL}^{2} \times$ $\mathrm{CO} 2$ experiment. The difference between the two, qECETCE, is defined here as the unrealized carbon uptake $\Delta C^{\mathrm{UNR}}$. Thus, $\Delta \mathrm{C}^{\mathrm{UNR}}$ reflects the difference in CE between the final condition of the $\mathrm{FULL}^{2} \times \mathrm{CO}^{2}$ experiment, and the condition where $\mathrm{CO}_{2}$ concentration is doubled in 1pctCO2. $\Delta C^{\mathrm{ADD}}$ is similar to $\Delta \mathrm{C}^{\mathrm{UNR}}$, but this quantity is defined as the CE difference between the two experiments when $\Delta \mathrm{T}$ reaches $\mathrm{qECS}$ in each experiment (as shown by the orange arrow in Fig. 4).

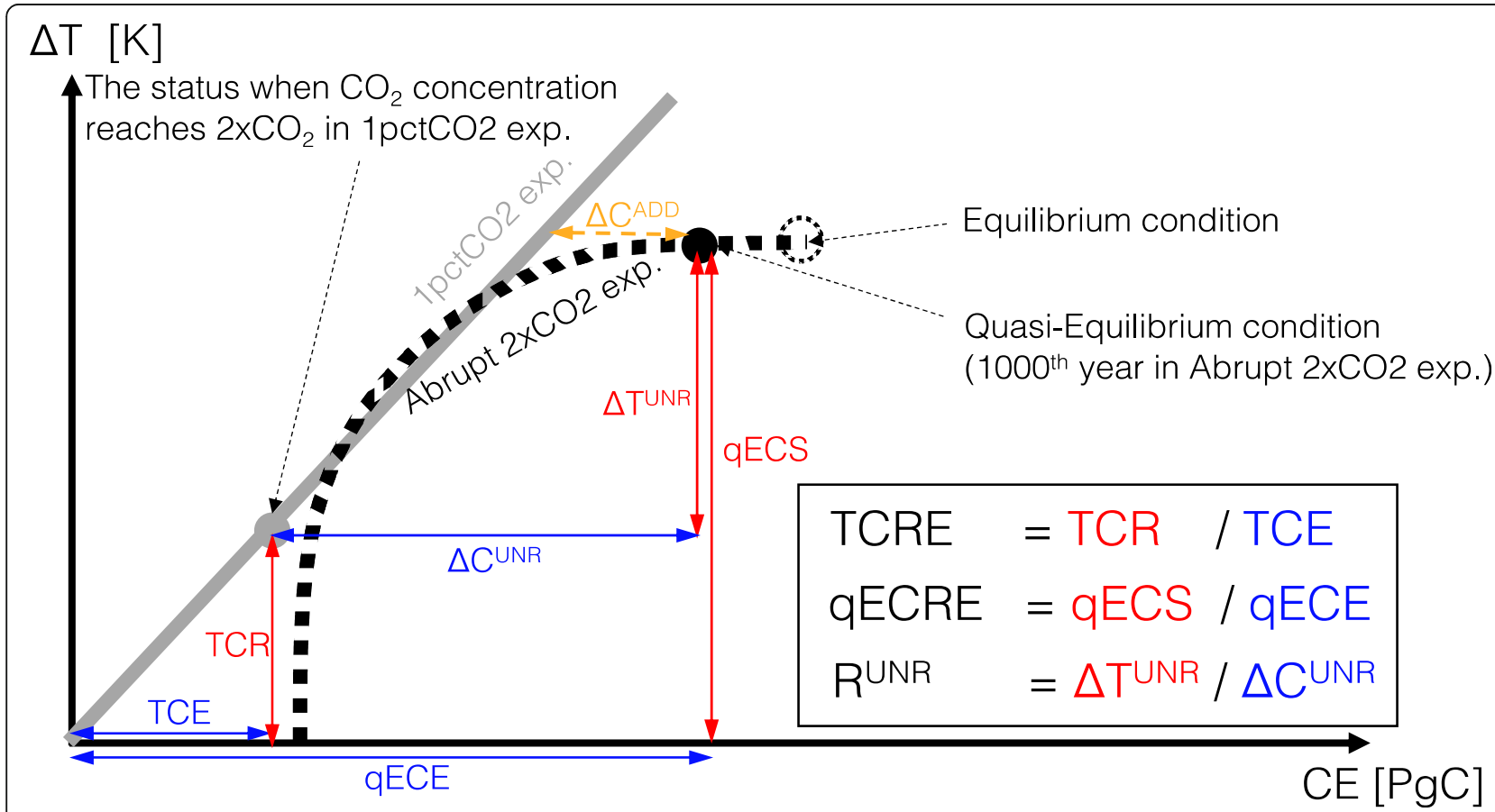

Fig. 4 Definitions of quantities for evaluating temperature and carbon (C) in 1 pctCO2 and $\mathrm{FULL}^{2} \times \mathrm{CO}^{2}$ experiments, illustrated in the context of global surface air temperature change $(\Delta T)$-cumulative anthropogenic $C$ emission (CE): transient climate response (TCR); transient $C$ emission (TCE); quasi-equilibrium climate sensitivity (qECS); quasi-equilibrium $C$ emission (qECE); unrealized warming $\left(\Delta T^{\mathrm{UNR}}\right.$ ); unrealized $\mathrm{C}$ uptake $\left(\Delta \mathrm{C}^{\mathrm{UNR}}\right)$; additional $C$ uptake $\left(\Delta C^{A D D}\right)$; transient climate response to cumulative $C$ emission (TCRE); quasi-equilibrium climate response to cumulative $C$ emission (qECRE); and the ratio of unrealized warming to unrealized $C$ uptake $\left(R^{U N R}\right)$. Note that TCRE is usually defined as the ratio of $\Delta T$ to $C E$ when $\mathrm{CE}$ reaches $1000 \mathrm{PgC}$, but we evaluate it here when the $\mathrm{CO}_{2}$ concentration in the 1 pctCO2 experiment reaches $2 \times \mathrm{CO}_{2}$ level 
The ratio of $\Delta \mathrm{T}$ to $\mathrm{CE}$ is called the transient climate response to cumulative $\mathrm{C}$ emission (TCRE), which is usually evaluated when CE reaches $1000 \mathrm{PgC}$. In this study, TCRE is evaluated at the time when the $\mathrm{CO}_{2}$ concentration reaches the $2 \times \mathrm{CO}_{2}$ level in the 1pctCO2 experiment. Similarly, the ratio of qECS to qECE is named here as the quasi-equilibrium climate response to cumulative $\mathrm{C}$ emission (qECRE). In addition, the ratio of unrealized warming $\left(\Delta \mathrm{T}^{\mathrm{UNR}}\right)$ to unrealized $C$ uptake $\left(\Delta \mathrm{C}^{\mathrm{UNR}}\right)$ is named here as $\mathrm{R}^{\mathrm{UNR}}$. If a model has a value for $\mathrm{R}^{\mathrm{UNR}}$ that is perfectly identical to the TCRE, the relationship TCRE $=R^{\mathrm{UNR}}=$ qECRE holds, presenting no difference between the 1 pctCO2 and $\mathrm{FULL}^{2} \times \mathrm{CO} 2$ experiments.

The $\Delta \mathrm{T}^{\mathrm{UNR}}$ and $\Delta \mathrm{C}^{\mathrm{UNR}}$ of MIROC-ESM were $1.0^{\circ} \mathrm{C}$ and $910 \mathrm{PgC}$, respectively, and thus $\mathrm{R}^{\mathrm{UNR}}$ of the model was about $1.13^{\circ} \mathrm{C} / \mathrm{EgC}$ (Table 3, Fig. 5). This $\mathrm{R}^{\mathrm{UNR}}$ only accounts for $51 \%$ of the TCRE, which is visualized in Fig. 5 as the decreasing slope of the $\triangle \mathrm{T}-\mathrm{CE}$ curve in the latter period of the FULL $^{2 \times \mathrm{CO}^{2}}$ experiment; the dissimilarity of the $\triangle \mathrm{T}-\mathrm{CE}$ relationship between the $\mathrm{FULL}^{2} \times \mathrm{CO} 2$ and 1 pctCO2 experiments is captured by the relatively small value of $R^{\mathrm{UNR}}$ when compared with TCRE. This suggests that in the model, global warming in the $\mathrm{FULL}^{2} \times \mathrm{CO} 2$ experiment is almost ceased/realized in the first 500-1000 years but cumulative C emission still continues beyond this time-scale-natural $\mathrm{C}$ uptake, in particular by the ocean, still continues even after the global warming is almost ceased. In MIROC-ES2L (Table 3, Fig. 5), $\Delta \mathrm{T}^{\mathrm{UNR}}$ and $\Delta \mathrm{C}^{\mathrm{UNR}}$ were respectively $0.94^{\circ} \mathrm{C}$ and $1024 \mathrm{PgC}$, and thus $\mathrm{R}^{\mathrm{UNR}}$ of this model becomes 0.91 . The
$\mathrm{R}^{\mathrm{UNR}}$ of MIROC-ES2L is $67 \%$ of the TCRE, indicating that $\triangle \mathrm{T}-\mathrm{CE}$ is relatively similar between $1 \mathrm{pctCO} 2$ and FULL ${ }^{2 \times}$ $\mathrm{CO} 2$ experiments, compared with MIROC-ESM. This suggests that the global warming and cumulative emission projected by MIROC-ES2L almost proceed in pace with each other in the FULL ${ }^{2} \times \mathrm{CO}^{2}$ experiment, as in the $1 \mathrm{pctCO} 2$ experiment.

\section{Comparison with other models: EMICs}

The two types of ESMs showed quite different values of $\mathrm{R}^{\mathrm{UNR}}$ and TCRE although both models belong to the same family of MIROC. To examine how $R^{\mathrm{UNR}}$ and TCRE are uncertain in existing models, the same analyses was applied to the simulation results of EMICAR5. Analysis of the results of the eight EMICs is shown in Fig. 5 and Table 3. Five of the eight EMICs (DCESS, GENIE, IGSM, MESMO, and UMD) showed the reduction in slope of $\triangle \mathrm{T}-\mathrm{CE}$ plot in the latter period of the FULL $^{2} \times \mathrm{CO}^{2}$ experiment-these models have lower $\mathrm{R}^{\mathrm{UNR}}$ than TCRE values, as in the MIROC-ESM simulations. Two of the models (Bern3D and MIROC3-liteLCM) showed almost similar values for both $R^{\mathrm{UNR}}$ and TCRE, thus the final condition of the 1000 year simulation dropped onto the $\triangle \mathrm{T}-\mathrm{CE}$ line of the $1 \mathrm{pctCO} 2$ simulation. One model, UVic ESCM, showed larger $\mathrm{R}^{\mathrm{UNR}}$ than TCRE. On average, all ten models including two ESMs and eight EMICs showed $1.87 \pm 0.38^{\circ} \mathrm{C} / \mathrm{EgC}$ for TCRE, $1.11 \pm 0.51{ }^{\circ} \mathrm{C} / \mathrm{EgC}$ for $\mathrm{R}^{\mathrm{UNR}}$, and $1.48 \pm$ $0.37^{\circ} \mathrm{C} / \mathrm{EgC}$ for qECRE (Table 3). The quantification of

Table 3 Comparison of temperature, carbon, and temperature-carbon quantities in two Earth system models and eight Earth systems Models of Intermediate Complexity

\begin{tabular}{|c|c|c|c|c|c|c|c|c|c|c|c|}
\hline \multirow{2}{*}{$\begin{array}{l}\text { Quantity category } \\
\text { Quantity name } \\
\text { [Unit] }\end{array}$} & \multicolumn{3}{|c|}{ Temperature quantities } & \multicolumn{4}{|c|}{ Carbon quantities } & \multicolumn{4}{|c|}{ Temperature-Carbon quantities } \\
\hline & $\begin{array}{l}\text { TCR } \\
{[\mathrm{K}]}\end{array}$ & $\begin{array}{l}\text { qECS } \\
{[\mathrm{K}]}\end{array}$ & $\begin{array}{l}\Delta T^{U N R} \\
{[K]}\end{array}$ & $\begin{array}{l}\mathrm{TCE} \\
{[\mathrm{PgC}]}\end{array}$ & $\begin{array}{l}\text { qECE } \\
{[\mathrm{PgC}]}\end{array}$ & $\begin{array}{l}\Delta \mathrm{C}^{\mathrm{UNR}} \\
{[\mathrm{PgC}]}\end{array}$ & $\begin{array}{l}\Delta C^{A D D} \\
{[\mathrm{PgC}]}\end{array}$ & $\begin{array}{l}\text { TCRE [KV } \\
\text { EgC] }\end{array}$ & $\begin{array}{l}\text { qECRE [K } \\
\text { EgC] }\end{array}$ & $\begin{array}{l}\mathrm{R}^{\mathrm{UNR}}[\mathrm{K} \\
\mathrm{EgC}]\end{array}$ & $\begin{array}{l}\mathrm{R}^{\mathrm{UNR}} / \mathrm{TCRE} \\
{[-]}\end{array}$ \\
\hline MIROC-ESM & 2.21 & 3.23 & 1.03 & 994 & 1904 & 910 & 392 & 2.22 & 1.70 & 1.13 & 0.51 \\
\hline MIROC-ES2L & 1.56 & 2.49 & 0.94 & 1148 & 2172 & 1024 & 262 & 1.36 & 1.15 & 0.91 & 0.67 \\
\hline Bern3D & 1.98 & 3.32 & 1.34 & 1002 & 1849 & 848 & 42 & 1.98 & 1.80 & 1.58 & 0.80 \\
\hline DCESS & 2.07 & 2.83 & 0.76 & 1006 & 2214 & 1207 & 629 & 2.05 & 1.28 & 0.63 & 0.31 \\
\hline GENIE & 2.47 & 3.98 & 1.51 & 1079 & 2354 & 1275 & 464 & 2.29 & 1.69 & 1.19 & 0.52 \\
\hline IGSM & 1.52 & 1.91 & 0.39 & 963 & 1888 & 925 & 647 & 1.58 & 1.01 & 0.42 & 0.27 \\
\hline MESMO & 2.41 & 3.70 & 1.29 & 968 & 1830 & 862 & 225 & 2.49 & 2.02 & 1.50 & 0.60 \\
\hline MIROC3-lite-LCM & 1.58 & 2.84 & 1.26 & 1031 & 2038 & 1006 & 45 & 1.53 & 1.39 & 1.25 & 0.82 \\
\hline UVic-ESCM & 1.94 & 3.49 & 1.55 & 1183 & 1959 & 776 & -326 & 1.64 & 1.78 & 2.00 & 1.22 \\
\hline UMD & 1.60 & 2.23 & 0.63 & 1009 & 2387 & 1378 & 669 & 1.59 & 0.94 & 0.46 & 0.29 \\
\hline Mean & 1.93 & 3.00 & 1.07 & 1038 & 2060 & 1021 & 305 & 1.87 & 1.48 & 1.11 & 0.60 \\
\hline S.D. & 0.36 & 0.66 & 0.39 & 75 & 209 & 201 & 322 & 0.38 & 0.37 & 0.51 & 0.30 \\
\hline Max & 2.47 & 3.98 & 1.55 & 1183 & 2387 & 1378 & 669 & 2.49 & 2.02 & 2.00 & 1.22 \\
\hline Min. & 1.52 & 1.91 & 0.39 & 963 & 1830 & 776 & -326 & 1.36 & 0.94 & 0.42 & 0.27 \\
\hline S.D./Mean & 0.19 & 0.22 & 0.36 & 0.07 & 0.10 & 0.20 & 1.05 & 0.20 & 0.25 & 0.46 & 0.49 \\
\hline
\end{tabular}

The quantities are defined in Fig. 4 

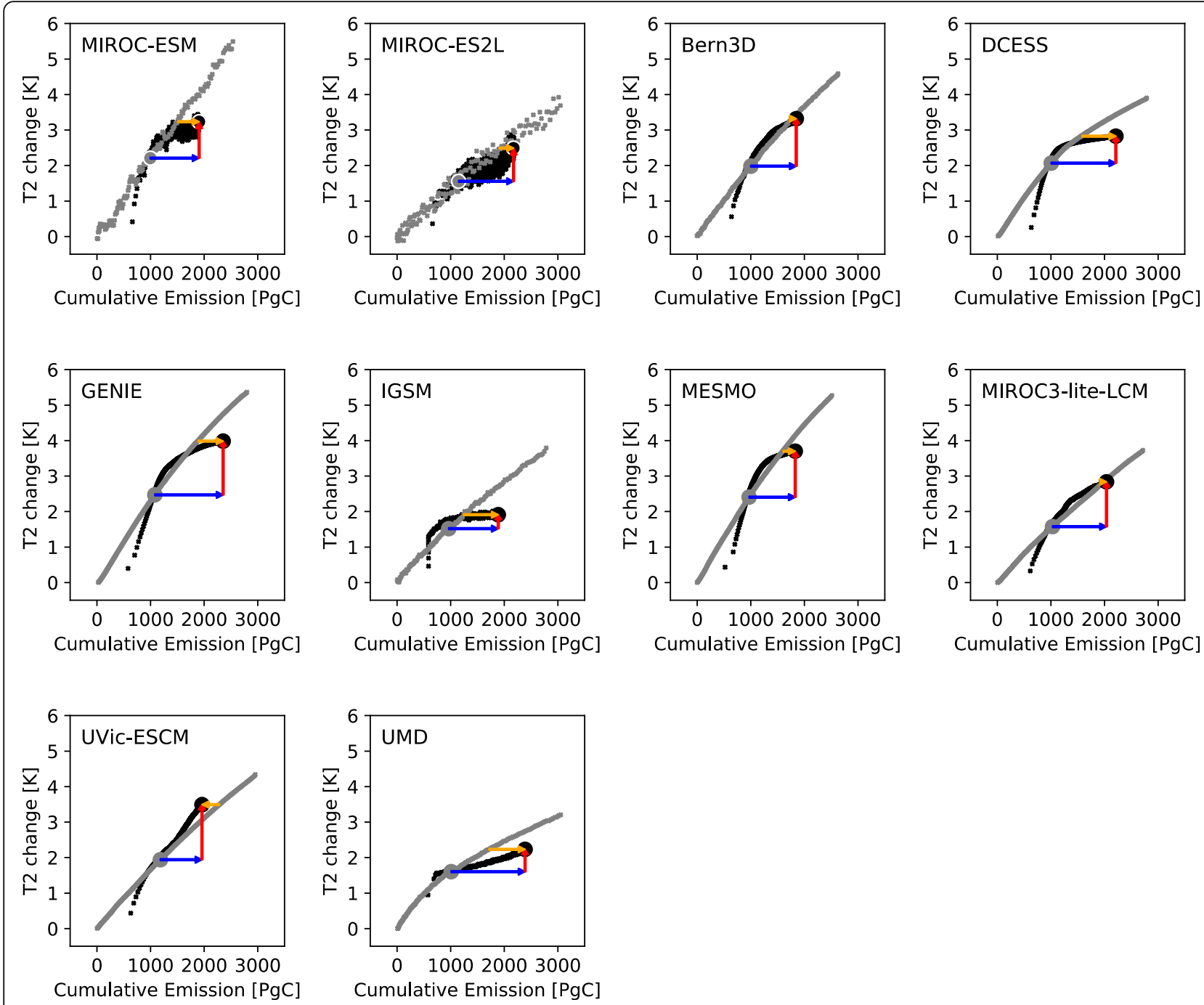

Fig. 5 Relationships between cumulative carbon $(C)$ emission and changes in global mean surface air temperature in the experiments of abruptly doubled $\mathrm{CO}_{2}$ concentration (FULL ${ }^{2} \times \mathrm{CO} 21000$ years; black) and that where $\mathrm{CO}_{2}$ concentration is increased by $1 \%$ year ${ }^{-1}$ (1 pctCO2; 140 years; gray) by two ESMs (MIROC-ESM and MIROC-ES2L) and eight EMICs from EMIC-AR5 (Eby et al. 2013; Zickfeld et al. 2013). Gray-filled circles represent the time when the $\mathrm{CO}_{2}$ concentration reaches about $2 \times \mathrm{CO}_{2}$ level in 1pctCO2 (calculated as the average of years 61-80); black-filled circles represent the final condition of the $\mathrm{FULL}^{2} \times \mathrm{CO}^{2}$ experiment (calculated as the average of years 981-1000). Red, blue, and orange arrows indicate the unrealized warming $\left(\Delta \mathrm{T}^{\mathrm{UNR}}\right)$, unrealized $\mathrm{C}$ uptake $\left(\Delta \mathrm{C}^{\mathrm{UNR}}\right)$, and additional $\mathrm{C}$ uptake $\left(\Delta \mathrm{C}^{\mathrm{ADD}}\right)$, as defined in Fig. 4

TCRE, $\mathrm{R}^{\mathrm{UNR}}$, and $\mathrm{qECRE}$ also revealed that the standard deviation relative to multi-model mean (the coefficient of variation, Table 3) was the largest for $\mathrm{R}^{\mathrm{UNR}}(0.46)$, followed by that of qECRE (0.25), and TCRE (0.20), suggesting the importance of constraining the long-term climate and $\mathrm{C}$ cycle responses beyond century time-scale in models. Although year 1000 was used in this study for calculating $\mathrm{R}^{\mathrm{UNR}}$ and $\mathrm{qECRE}$, the values are likely to become smaller in many models if we extend the simulation (e.g., up to more than a few thousands of years) and use the result for calculating the $\mathrm{R}^{\mathrm{UNR}}$ and qECRE because oceanic $C$ uptake likely persists beyond 1000 years.

If $\mathrm{R}^{\mathrm{UNR}}$ is smaller than TCRE, it should be accompanied by positive $\Delta \mathrm{C}^{\mathrm{ADD}}$, as indicated by the orange arrows in Figs. 4 and 5 . The positive $\Delta C^{\mathrm{ADD}}$ means that the $\mathrm{C}$ emission that is eventually achieved by the end of 1000 years simulation should be larger than the cumulative value that is estimated from $1 \mathrm{pctCO}$. This is owing to the long-lasting $\mathrm{C}$ uptake by the ocean, and the $\Delta \mathrm{C}^{\mathrm{ADD}}$ was $305 \pm 322 \mathrm{PgC}$ (Table 3; a demonstration by a simple climate model to estimate $\Delta C^{\mathrm{ADD}}$ in other climate stabilization scenarios can be found in Fig. S7).

\section{Difference in ocean heat and $\mathrm{C}$ uptake}

In the above discussion, we have confirmed that both ESMs showed smaller $\mathrm{R}^{\mathrm{UNR}}$ than TCRE, particularly for MIROC-ESM (Table 3); this was also confirmed in many (five of eight) EMICs. In MIROC-ESM, much of the 
global warming was already realized by around year 250, and the global warming almost ceased after 1000 years (Fig. 1a). However, ocean $\mathrm{C}$ uptake was still present beyond 1000 years (Fig. 1c), leading to the long-lasting anthropogenic $\mathrm{C}$ emission (Fig. 2) and increase in cumulative emission (Fig. 3; Fig. S2). As a result, the $\triangle \mathrm{T}-\mathrm{CE}$ relationship, which is usually visualized as an almost linear line on the $\Delta \mathrm{T}-\mathrm{CE}$ plot when using the 1 pctCO2 experiment or other historical/future simulation results, became non-linear in the 2000-year simulation (Fig. 3). These results suggest that long-lasting ocean $\mathrm{C}$ uptake will be a key for understanding the $\Delta \mathrm{T}-$ $\mathrm{CE}$ relationship in millennium time-scale simulations.

In addition to the important role of the ocean in the long-term $\mathrm{C}$ budget, the ocean has been implicated in the control of long-term global warming by absorbing excess heat from the atmosphere, until the outgoing longwave radiation into space counterbalances radiative forcing. Previous studies have suggested that these heat and $\mathrm{C}$ uptakes by the ocean likely proceed in pace with each other because both processes are controlled by the same oceanic processes such as wintertime deep convection in polar regions and deep ocean circulation that distributes absorbed excess heat and anthropogenic C over the global oceans (e.g., Jones et al. 2016; MacDougall 2017). Indeed, a multi-model study using CMIP5 ESMs demonstrated the almost similar spatiotemporal pattern of ocean heat and C uptake (Frölicher et al. 2015). Ehlert and Zickfeld (2017) noted in their longterm simulation study on ZEC that thermal equilibrium is likely faster than biogeochemical equilibrium, but they attributed it to the long time-scales of sediment $\mathrm{C}$ cycle processes. This widespread understanding appears to be contradictory to the results of this study, which shows that $\mathrm{C}$ uptake by the ocean likely continues longer than ocean heat uptake. Indeed, the shape of the curve of annual ocean heat uptake plotted against cumulative ocean $\mathrm{C}$ uptake is quite similar to the shape of the $\triangle \mathrm{T}-\mathrm{CE}$ curve in the FULL ${ }^{2} \times \mathrm{CO}^{2}$ experiments in the two ESMs and seven EMICs (Fig. 6, in which one EMIC (UMD) is omitted because the data on ocean heat uptake of the model was not available). This suggests that the longterm response of the ocean forms the shape of the $\Delta \mathrm{T}-$ $\mathrm{CE}$ plots and that the ocean heat uptake and $\mathrm{C}$ uptake beyond centuries proceed at different paces, resulting in relatively smaller $R^{\mathrm{UNR}}$ than TCRE values.

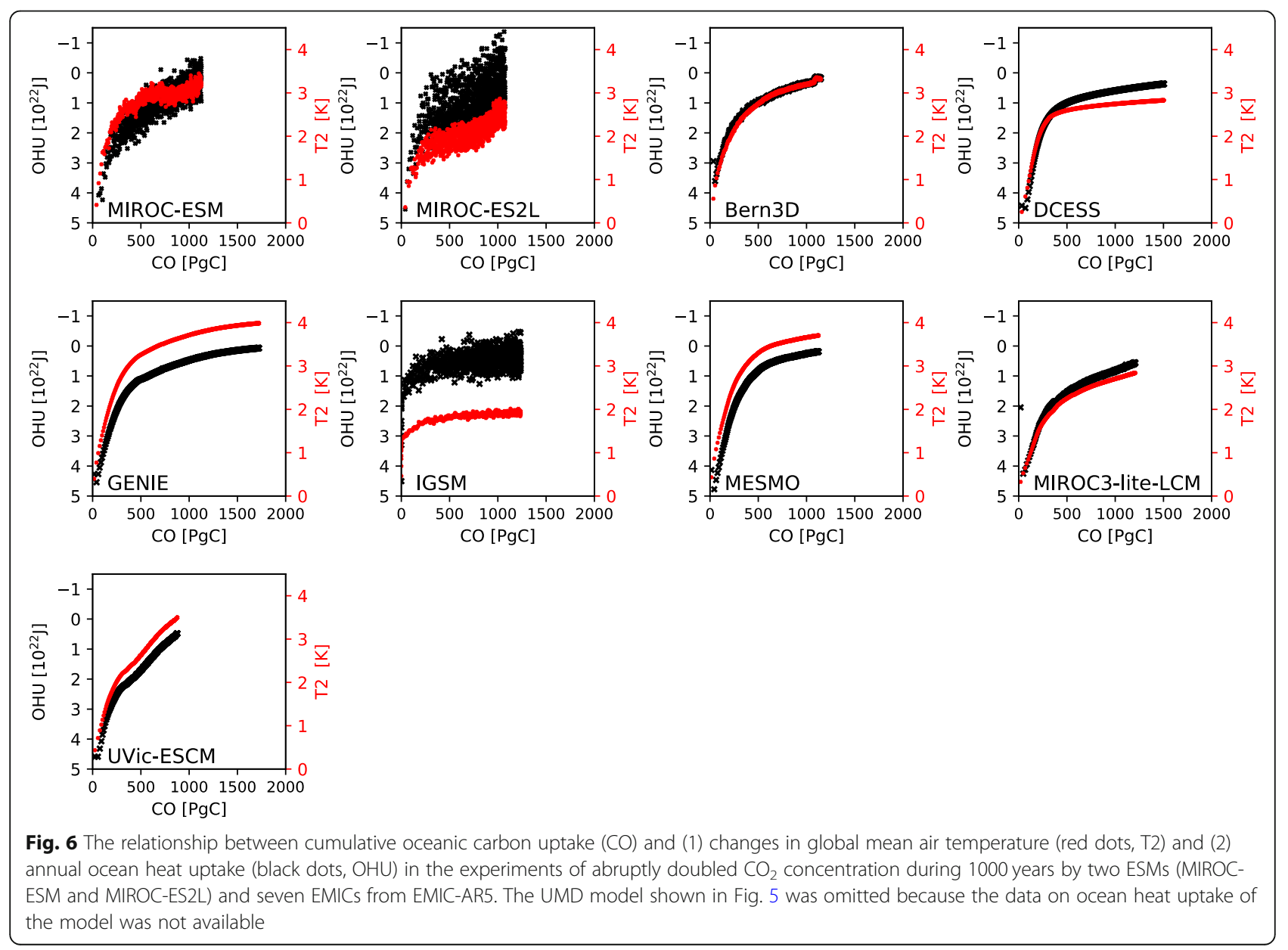


To explore the mechanism behind the different rate of the two processes, we examined the propagation of heat and $\mathrm{C}$ in the ocean in the $\mathrm{FULL}^{2} \times \mathrm{CO}^{2}$ experiment by MIROC-ESM. Figure 7 shows the result in the Atlantic. Note that the $\mathrm{RAD}^{2} \times \mathrm{CO}^{2}$ experiment is used for the analysis of heat transport and that the $\mathrm{BGC}^{2} \times \mathrm{CO}^{2}$ experiment is used for $\mathrm{C}$, so as to separately discuss the effect of $\mathrm{CO}_{2}$ doubling on the ocean heat and $\mathrm{C}$ uptakes (the figures for the $\mathrm{FULL}^{2} \times \mathrm{CO}^{2}$ experiment can be found in Figs. S3 and S4, respectively).

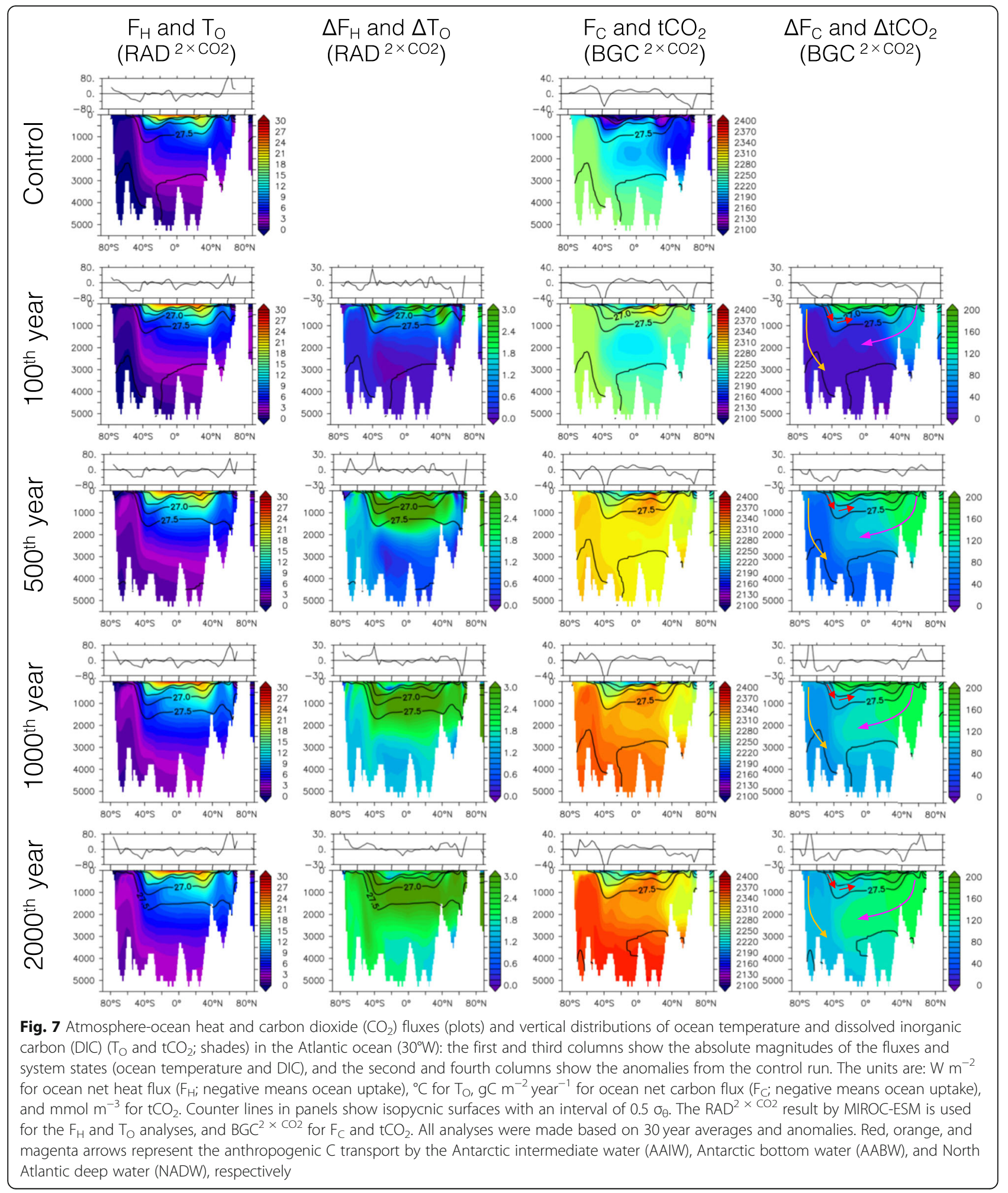


In the pre-industrial condition (top panels in Fig. 7), the ocean temperature above the $1000 \mathrm{~m}$ depth is relatively warm in the region $40^{\circ} \mathrm{S}-40^{\circ} \mathrm{N}$ and stratified as characterized by the thermocline, which is roughly located between the 26.5-27.0 $\sigma_{\theta}$ isopycnal surfaces; the ocean $C$ is relatively poor above the thermocline. One hundred years after the abrupt $\mathrm{CO}_{2}$ doubling, the surface ocean above the thermocline in the region $40^{\circ} \mathrm{S}-40^{\circ} \mathrm{N}$ was filled with warmed waters (2nd row in Fig. 7). As schematically explained by Goodwin et al. (2015), this relatively fast uptake of heat is likely based on the processes of the surface turbulent mixed layer development and the warmed water subduction from surface into thermocline along with the isopycnal surfaces. As time passes, the heat is further transported downward, seemingly attributed to both of the above-mentioned warmed water subduction processes and the ocean heat uptake associated with the formation of North Atlantic deep water (NADW) and Antarctic bottom water $(\mathrm{AABW})$. Additionally, diapycnal mixing and resultant downward heat flux across isopycnal surfaces could accelerate the warming above and around the thermocline. Deep-ocean warming became apparent in the Southern Ocean until year 500 (3rd row in Fig. 7), which was likely related to the recovery of deep convection in the Weddell Sea (Yamamoto et al. 2015; Obase et al. 2017). Finally, at the end of the 2000 year-long simulation, the entire Atlantic was warmed.

When compared with the heat transport, the spatial and temporal change in $\mathrm{C}$ transport into deeper ocean showed a distinct pattern (the third and fourth columns of Fig. 7), particularly beyond a few centuries. In the first 100 years, the upper ocean, where seawater is well mixed and ventilated, was filled by the anthropogenic $C$ similarly to that of heat uptake. In addition, the North Atlantic also showed moderate anthropogenic $\mathrm{C}$ uptake. This relatively fast (decadal to centennial) uptake of anthropogenic $\mathrm{C}$ into the thermocline and deeper layers in the North Atlantic was also confirmed in the observational study on ocean C inventory (Sabine et al. 2004; Gruber et al. 2019) and in centennial simulations by CMIP5 and CMIP6 ESMs (Frölicher et al. 2015; Arora et al. 2020). After that, unlike the heat transport, a large part of the anthropogenic $\mathrm{C}$ remained above the thermocline in the region $40^{\circ} \mathrm{S}-40^{\circ} \mathrm{N}$, while the anthropogenic $\mathrm{C}$ absorbed in the high-latitude formation region of NADW was transported into intermediate/deep layers mainly along the lower equatorward branch of the Atlantic Meridional Overturning Circulation (magenta arrows in the third to fifth row of Fig. 7). Again, we note that the $\mathrm{BGC}^{2 \times \mathrm{CO} 2}$ simulation was used for this $\mathrm{C}$ uptake analysis, and thus the warming effects on the ocean dynamics can be ignored here.

Like the Atlantic, the surface water in the Pacific also quickly accumulated and transported the anthropogenic
$\mathrm{C}$ into the thermocline within a century, and the structure where much of the anthropogenic $C$ was trapped in the upper ocean persisted afterwards (Fig. 8). Unlike the Atlantic, there was less anthropogenic $\mathrm{C}$ transport into intermediate/deep layers in the Northern hemisphere because there was no deep water formation in the subarctic North Pacific. As a result, the content of anthropogenic $\mathrm{C}$ in the intermediate and deep layers was maintained for a long time at levels that were not largely different from those in the pre-industrial condition. The anthropogenic $\mathrm{C}$ was gradually transported into deeper layers along the northward intrusion of AABW, but even after 2000 years, the ocean still had potential for anthropogenic $C$ uptake.

\section{The possible reasons for non-linear T-CE relationship in millennium-scale experiments}

Our simulations show that, on a centennial time-scale, ocean heat and $\mathrm{C}$ uptake both proceeded in a similar manner-they occurred in the well-ventilated upper ocean, likely relying on the processes of surface mixing, and warmed, C-rich water subduction into the thermocline, as suggested by previous studies (e.g., Goodwin et al. 2015; Frölicher et al. 2015; Williams et al. 2016; Arora et al. 2020). Additionally, the formation of NADW and associated equatorward flow are also confirmed to play an important role for $\mathrm{C}$ transport on this time-scale. Within a few centuries, ocean heat and $C$ uptakes proceeded in a similar manner and at similar rates, but they were not exactly the same; thus, partially opposing effects of oceanic uptake of heat and $\mathrm{C}$ act to remain the almost constant TCRE on multi-decadal to centennial time-scales (Goodwin et al. 2015; Williams et al. 2016). Over centuries to millennia, however, the behavior of ocean heat and $\mathrm{C}$ uptake is found to be decoupled, and the dominant process in this time-scale changes to the slow ventilation of the intermediate and deep ocean (Figs. 7 and 8; Goodwin et al. 2015). This suggest that the key process to understand the different pace of ocean heat and $\mathrm{C}$ uptake beyond centuries exists in the ventilation processes of the intermediate and deep ocean.

One of the possible reasons for such different behavior of ocean heat and $\mathrm{C}$ transport into deeper ocean over centuries could be explained by the difference in the time-scales of air-sea exchange of heat and C. The ocean surface water reaches the equilibrium of air-sea heat exchange within a month, while air-sea $\mathrm{CO}_{2}$ exchange, which is buffered by $\mathrm{CO}_{2}$ dissolution and carbonate chemistry in the seawater, occurs over months or about a year (Frölicher et al. 2015; Jones et al. 2014). As a result of the slow air-sea exchange of $\mathrm{CO}_{2}$, a large part of the surface water is subducted into the ocean interior before reaching air-sea $\mathrm{CO}_{2}$ equilibrium, producing a large $\mathrm{C}$ deficit between the actual $\mathrm{C}$ amount in seawater 


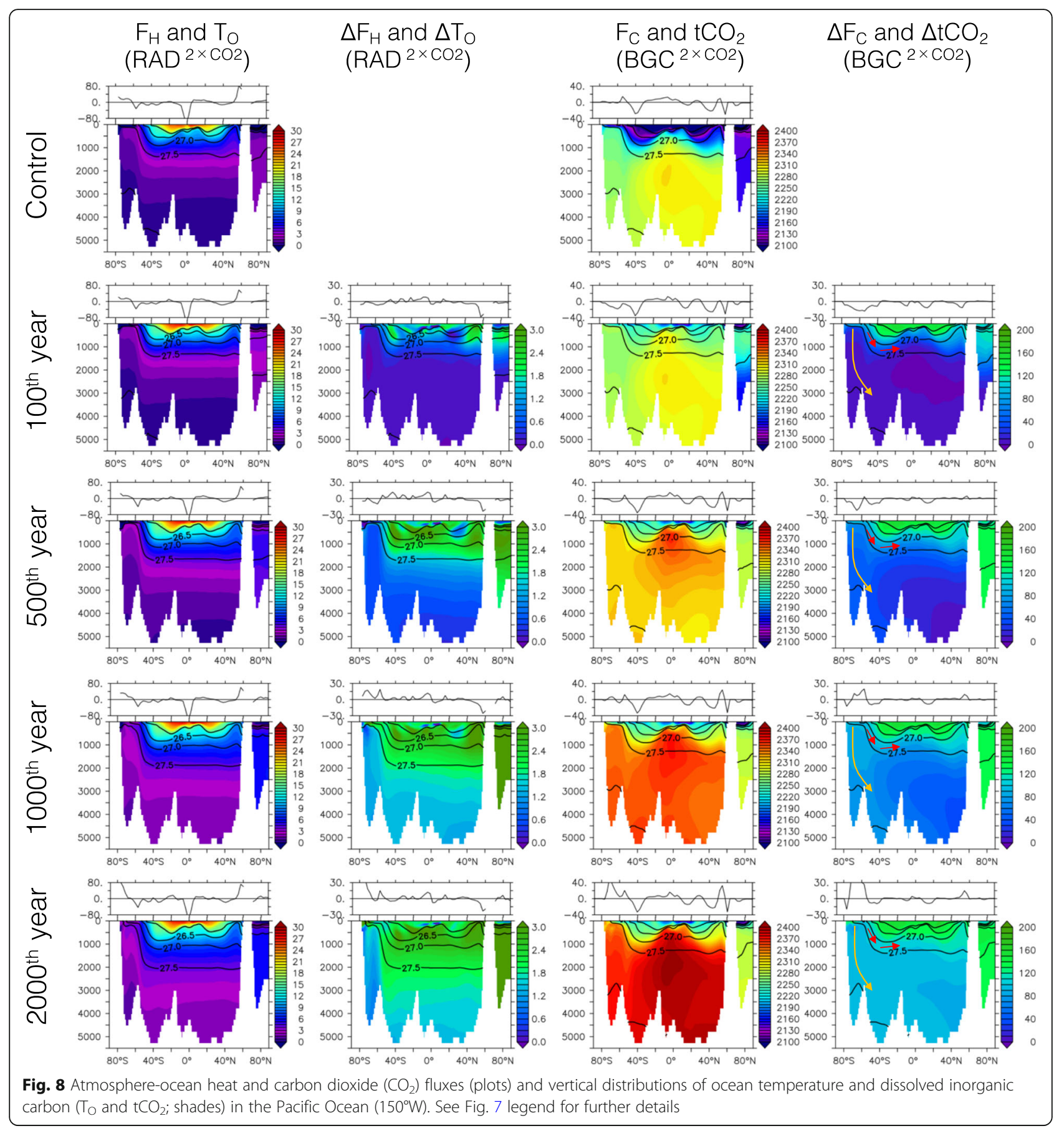

and the amount of $\mathrm{C}$ that can potentially be contained under air-sea equilibrium. Thus, the $\mathrm{C}$ deficit, called the "C disequilibrium" or "unsaturated C" component (Ito and Follows 2005; Jones et al. 2014; Schwinger and Tjiputra 2018; Arora et al. 2020), mainly reflects how long the ocean surface is exposed to the atmosphere. A study based on centennial time-scale simulations by Arora et al. (2020) compared this $C$ disequilibrium component among CMIP6 ESMs, and they clearly showed that C disequilibrium is the main driver to keep anthropogenic
$\mathrm{C}$ in intermediate and deep water at relatively low levels. Although their study was based on much shorter simulations ( 150 years) than ours, the $\mathrm{C}$ disequilibrium component, which is originally derived from the slow rate of air-sea $\mathrm{CO}_{2}$ exchange, could also explain the low level of anthropogenic $\mathrm{C}$ in intermediate and deep layers beyond centuries to millennia.

Another possible mechanism could be associated with the heat and $\mathrm{C}$ uptake in the Southern Ocean. The Southern Ocean is the dominant region for global heat 
and $\mathrm{C}$ uptake, and about $75 \%$ and $43 \%$ of heat and C, respectively, are estimated to be absorbed there based on CMIP5 simulations (Frölicher et al. 2015). This significant contribution of the Southern Ocean is maintained by upwelling of cold and low anthropogenic $\mathrm{C}$ water from deeper layers to the surface; the upwelled water is transported northwards mainly by the surface winddriven Ekman flow, with uptake of heat and anthropogenic $\mathrm{C}$ from the atmosphere; a certain fraction of the surface water is subducted again into the ocean interior; this provides a pathway of warmed and C-rich surface water into the ocean interior, making the thermocline the main storage mechanism of excess heat and anthropogenic $\mathrm{C}$ in decadal to centennial time-scales; the formation of Antarctic intermediate water in the region around $50^{\circ} \mathrm{S}-40^{\circ} \mathrm{S}$ transports the anthropogenic $\mathrm{C}$ into intermediate layers of around $1000 \mathrm{~m}$ depth; the anthropogenic $C$ can also be transported into deeper layers by AABW (Sabine et al. 2004; Iudicone et al. 2016; Jones et al. 2014; Gruber et al. 2019). The $C$ uptake from the atmosphere into the Southern Ocean, however, only accounts for $43 \%$ of global ocean C uptake-this contribution is large but much less than that of heat uptake in this region (75\%; Frölicher et al. 2015), suggesting a low efficiency of oceanic $\mathrm{C}$ uptake in this region compared with heat uptake. Indeed, the amount of anthropogenic $\mathrm{C}$ on the transport pass of the Antarctic intermediate water (AAIW; the red arrows in Figs. 7 and 8, which almost corresponded to the potential density of AAIW of $27.0 \sigma_{\theta}-27.55 \sigma_{\theta}$ ) is clearly lower than that in the above layers; in particular, the anthropogenic $\mathrm{C}$ minimum of AAIW is found clearly in the Atlantic Ocean, at year 500 and later in the $\mathrm{FULL}^{2} \times \mathrm{CO}^{2}$ (rightmost column in Fig. 7); in the Pacific, the anthropogenic $\mathrm{C}$ of AAIW and of the layers below clearly maintains a lower amount of anthropogenic C over the whole 2000 years (Fig. 8). Similarly, the AABW (shown by orange arrows in Figs. 7 and 8) also contains low levels of anthropogenic C. These low levels of anthropogenic $\mathrm{C}$ in the intermediate and deep layers are also confirmed in the $\mathrm{FULL}^{2} \times \mathrm{CO} 2$ by MIROC-ES2L (Figs. S5 and S6).

The low level of anthropogenic $C$ in the water mass formed in the Southern Ocean (AAIW and AABW) might be attributable to the $C$ disequilibrium component as discussed above, which is further associated with the mixed layer depth, buffering effect of $\mathrm{C}$ chemistry, existence of sea ice, and other factors like residence time of upwelled water in this region (Jones et al. 2014). In addition, because the upwelled water in the Southern Ocean is cold but already contains abundant $\mathrm{C}$ because of the long-term biological effects, the upwelled cold water could more effectively take up the heat from the atmosphere than $\mathrm{C}$. For more detail, we need further examination of the mechanism to produce the low level of anthropogenic $\mathrm{C}$ in the Southern Ocean, hopefully based on multi-model comparison. In particular, the regenerated $\mathrm{C}$ component, which is one of the oceanic inorganic $\mathrm{C}$ components caused by biological regeneration of organic $\mathrm{C}$, might be associated with the millenniumlong processes; the regenerated $\mathrm{C}$ can contribute to $\mathrm{C}$ accumulation in intermediate and deeper layers and thus it may partly accelerate the $\mathrm{C}$ uptake, in particular under the effect of global warming (e.g., Schwinger and Tjiputra 2018; Arora et al. 2020).

In the section above, to explain the situation when $\mathrm{R}^{\mathrm{UNR}}$ is smaller than TCRE (Figs. 3 and 5), we have discussed the decoupled behavior of the ocean heat and $\mathrm{C}$ uptake beyond centuries, by attributing it to the $\mathrm{C}$ disequilibrium component and the role of the Southern Ocean. Additionally, MacDougall (2017) suggested based on a theoretical framework that constant TCRE can be realized for a limited range of emission rates and that constant TCRE cannot be maintained when emission rates are very high or very low. Indeed, in the FULL ${ }^{2} \times$ $\mathrm{CO} 2$ and 1pctCO2 simulations, the two experiments overlap when diagnosed emissions are in the mid-range of emission rates and diverge when the emission rates are very high $\left(>20 \mathrm{PgC}_{\text {year }}{ }^{-1}\right)$ and very low $(<1 \mathrm{PgC}$ year $^{-1}$ ). Thus, even if the ocean heat and $C$ uptake processes remained tightly coupled beyond centuries, we might expect the relationship between global warming and cumulative $\mathrm{C}$ emission to be non-linear based on the emission rate (MacDougall 2017; Seshadri 2017).

\section{Summary and conclusions}

In this study, by using two ESMs, we performed idealized climate- $\mathrm{C}$ cycle simulations where the atmospheric $\mathrm{CO}_{2}$ concentration was abruptly doubled from preindustrial state and fixed at that level over a millennial time-scale $\left(\mathrm{FULL}^{2} \times \mathrm{CO}^{2}, \mathrm{BGC}^{2 \times \mathrm{CO}^{2}}\right.$, and $\mathrm{RAD}^{2 \times \mathrm{CO}^{2}}$ ); the analysis mainly focused on the relationship between global temperature change and diagnosed anthropogenic emission. The results were compared with another idealized experiment, 1 pctCO2, where the $\mathrm{CO}_{2}$ concentration is increased by $1 \%$ per year, and we confirmed that the $\triangle \mathrm{T}-\mathrm{CE}$ relationship was not linear in the $\mathrm{FULL}^{2} \times \mathrm{CO} 2$ experiment when compared with that of $1 \mathrm{pctCO} 2$, although the degree of similarity of the $\Delta \mathrm{T}-\mathrm{CE}$ plot between the two experiments was dependent on the model. One model, MIROC-ESM, showed a relatively large discrepancy on the $\triangle \mathrm{T}-\mathrm{CE}$ plot between $\mathrm{FULL}^{2} \times$ $\mathrm{CO} 2$ and 1 pctCO2 experiments, which was quantitatively captured by the relatively smaller $\mathrm{R}^{\mathrm{UNR}}$ (the ratio of unrealized warming to unrealized $C$ uptake in the latter part of the $\mathrm{FULL}^{2} \times \mathrm{CO}^{2}$ experiment) than the TCRE (which was evaluated at the doubled $\mathrm{CO}_{2}$ level in the 1 pctCO2 experiment). This smaller $\mathrm{R}^{\mathrm{UNR}}$ than TCRE was also confirmed in EMICs, but the degree of 
mismatches between $\mathrm{R}^{\mathrm{UNR}}$ and TCRE was dependent on the models, suggesting that large uncertainty exists in both $\Delta \mathrm{T}$ and $\mathrm{CE}$ in the long-term climate-C cycle simulations by existing models. On average, all 10 models including two ESMs and eight EMICs showed $1.87 \pm$ $0.38^{\circ} \mathrm{C} / \mathrm{EgC}$ for TCRE, $1.11 \pm 0.51^{\circ} \mathrm{C} / \mathrm{EgC}$ for $\mathrm{R}^{\mathrm{UNR}}$, and $1.48 \pm 0.37^{\circ} \mathrm{C} / \mathrm{EgC}$ for qECRE.

In the latter period of the millennium time-scale experiment, $\mathrm{R}^{\mathrm{UNR}}$ became relatively smaller than TCRE because in this period global warming is almost ceased but the ocean continues to take up C. By considering that long-term global temperature is tightly associated with ocean heat uptake, it is interesting that the small $\mathrm{R}^{\mathrm{UNR}}$ relative to TCRE suggests that the ocean continues to take up $\mathrm{C}$ longer than it takes up heat. However, this is contradictory to the widespread understanding of the role of the ocean in long-term climate and $\mathrm{C}$ cycles-the ocean continues to take up heat and $\mathrm{C}$ in pace with each other because deep ocean circulation dominates both processes, and thus global warming and ocean $\mathrm{C}$ uptake are expected to continue/cease with the same pace. In our study, ESMs showed that the ocean heat propagated into deeper ocean in a straight downward manner, while ocean $\mathrm{C}$ transport seemed strongly dominated by the meridional overturning circulations. Because of this, ocean $\mathrm{C}$ transport into the deeper ocean slowed, taking more time to dominate and saturate with anthropogenic $\mathrm{C}$ throughout the depth of the water column, and leading to the time-lag of ceasing of ocean $\mathrm{C}$ uptake behind the ceasing of global warming. We raised two possibilities ( $C$ disequilibrium component and the role of the Southern Ocean) to explain this decoupled behavior of ocean heat and $\mathrm{C}$ uptake beyond centuries, but further multi-model analysis would be necessary to clarify the detailed mechanism behind this difference.

If models have relatively smaller $\mathrm{R}^{\mathrm{UNR}}$ than TCRE, they should have larger $C E$ at the end of 1000 years simulation than $\mathrm{CE}$ that is evaluated when global warming reaches qECS in the 1 pctCO2 experiment. This deficit was quantified as $\Delta C^{\mathrm{ADD}}$, and many models projected positive values for $\Delta \mathrm{C}^{\mathrm{ADD}}$, indicating that if we aim to stabilize the $\mathrm{CO}_{2}$ concentration and the subsequent climate stabilization over centuries to millennia, we can emit $C$ by $\Delta C^{A D D}$ in addition to the $C E$ estimated from the linear $\Delta \mathrm{T}-\mathrm{CE}$ plot of $1 \mathrm{pctCO}$.

The experimental design employed in this study was highly idealized (abruptly doubling $\mathrm{CO}_{2}$ concentration over 1000-2000 years), and thus the direct translation of the simulation results to policy-relevant messages might be difficult. However, performing such experiments by using ESMs can lead us to a fundamental understanding on how the climate- $\mathrm{C}$ cycle system proceeds on the millennium time-scale, as partly performed in this study. In particular, the examination of (quasi)equilibrium states of the climate-C cycle system, which were evaluated by $\mathrm{qECS}, \mathrm{qECE}$, and $\mathrm{qECRE}$ in this study, might provide more basic properties of models because these indices are independent of the choice of scenario (the pathway to reach the doubled $\mathrm{CO}_{2}$ level) and rely on the magnitude of external forcing (and simulation length), as traditionally examined in the physical climate science field. The examination revealed that larger uncertainty exists in $\mathrm{R}^{\mathrm{UNR}}$ than TCRE, suggesting the importance of constraining the long-term response of the climate-C cycle system in models.

In this study, only two ESMs were used for the analysis, but to confirm the robustness of the conclusions, it is desirable to perform similar simulations by multiple ESMs, as performed by a model intercomparison project "LongRunMIP" by Rugenstein et al. (2019). Although the simulations proposed in this study are computationally expensive and other possible experimental designs exist (e.g., a pulse emission scenario as used in Archer et al. 2009; Frölicher et al. 2013; Joos et al. 2013), the experiments performed in this study are quite simple. Because the abrupt increase in $\mathrm{CO}_{2}$ (quadrupling) scenario was already embedded as one of the fundamental experiments of CMIP5 and CMIP6, extending the simulation up to 1000 years was not difficult and thus this simple design might be favored by modeling centers. Furthermore, a part of the simulations can be performed by offline models (e.g., the $\mathrm{BGC}^{2} \times \mathrm{CO}^{2}$ simulation could be performed by off-line land/ocean models with biogeochemistry; the $\mathrm{RAD}^{2} \times \mathrm{CO}_{2}$ experiment could be performed by AOGCMs). Performing millennium timescale simulations by a hierarchy of climate models (ESMs, AOGCMs, EMICs, and simplified climate models) and comparison of the results will help to obtain further insight on climate-C cycle processes and to understand the long-term response of the Earth system to anthropogenic perturbations.

\section{Supplementary information}

Supplementary information accompanies this paper at https://doi.org/10. 1186/s40645-020-00350-2.

Additional file 1:. Supplemental Materials

\section{Abbreviations}

AABW: Antarctic bottom water; AAIW: Antarctic intermediate water; AOGCMs: Atmosphere-ocean general circulation models; CMIP: Coupled model intercomparison project; C4MIP: The Coupled Carbon Cycle Climate Model Intercomparison Project; ECS: Equilibrium climate sensitivity; EMICs: Earth systems models of intermediate complexity; ESMs: Earth system models; MIROC: The Model for Interdisciplinary Research on Climate; MIROCESM: The Model for Interdisciplinary Research on Climate, the Earth System Model; MIROC-ES2L: The Model for Interdisciplinary Research on Climate, the Earth System model version2 for Long-term simulations; NADW: North

Atlantic deep water; qECS: Quasi-equilibrium climate sensitivity; qECE: Quasiequilibrium cumulative emission; qECRE: Quasi-equilibrium climate response to cumulative carbon emission; TCE: Transient cumulative emission; 
TCR: Transient climate response; TCRE: Transient climate response to cumulative emission; ZEC: Zero emission commitment

\section{Acknowledgements}

We greatly appreciate the valuable comments from the two reviewers Chris Jones and an anonymous referee. The authors appreciate the data providers/modelers participating in EMIC-AR5, and data archiving support by M. Abe and O. Arakawa. The Super Computing System in JAMSTEC, the Earth Simulator, was used for the simulations. Kaoru Tachiiri, Junichi Tsutsui, and Tomoo Ogura provided helpful and encouraging comments. We thank Catherine Dandie, PhD, from Edanz Group (https://en-author-services.edanzgroup. com/expert/soil-sciences/catherine-dandie) for editing a draft of this manuscript and helping to draft the abstract.

\section{Authors' contributions}

TH designed the experiments, performed simulations and analysis, and drafted the entire document. AY and MK contributed to the analysis and drafting. RO performed a part of the simulation of the CTL run. MW and HT contributed the physical oceanic analysis. XS supported the analysis of longterm global warming and natural carbon uptake. All authors read and approved the final manuscript.

\section{Funding}

This work was supported by TOUGOU/SOUSEl, the "Integrated Research Program for Advancing Climate Models (grant number JPMXD0717935715)"/ "Program for Risk Information on Climate Change", by the Ministry of Education, Culture, Sports, Science, and Technology of Japan.

\section{Availability of data and materials}

The simulation outputs of the CTL, FULL ${ }^{2 \times \mathrm{CO}^{2}}$, and 1 pctCO2 simulations by MIROC-ESM and MIROC-ES2L are distributed and made freely available through the Earth System Grid Federation (ESGF). Details on the ESGF can be found on the website of the CMIP Panel (https://www.wcrp-climate.org/ wgcm-cmip/). Readers are requested to contact the corresponding author if they wish to obtain the outputs of the $\mathrm{BGC}^{2 \times \mathrm{CO} 2}$ and $\mathrm{RAD}^{2 \times \mathrm{CO} 2}$ simulations. The simulation results of EMICs were obtained from the EMIC-AR5 website (http://climate.uvic.ca/EMICAR5/)

\section{Competing interests}

The authors declare that they have no competing interest.

Received: 30 December 2019 Accepted: 8 July 2020

Published online: 24 August 2020

\section{References}

Allen MR, Frame DJ, Huntingford C, Jones CD, Lowe JA, Meinshausen M, Meinshausen N (2009) Warming caused by cumulative carbon emissions towards the trillionth tonne. Nature 458:1163-1166. https://doi.org/10.1038/ nature08019

Andrews T, Gregory JM, Webb MJ, Taylor KE (2012) Forcing, feedbacks and climate sensitivity in CMIP5 coupled atmosphere-ocean climate models. Geophys Res Lett 39:1-7. https://doi.org/10.1029/2012GL051607

Archer D, Eby M, Brovkin V, Ridgwell A, Cao L, Mikolajewicz U, Caldeira K, Matsumoto K, Munhoven G, Montenegro A, Tokos K (2009) Atmospheric lifetime of fossil fuel carbon dioxide. Annu Rev Earth Planet Sci 37:117-134. https://doi.org/10.1146/annurev.earth.031208.100206

Arora VK, Boer GJ, Friedlingstein P, Eby M, Jones CD, Christian JR, Bonan G, Bopp L, Brovkin V, Cadule P, Hajima T, Iyina T, Lindsay K, Tjiputra JF, Wu T (2013) Carbon-concentration and carbon-climate feedbacks in CMIP5 Earth system models. J Clim 26:5289-5314. https://doi.org/10.1175/JCLI-D-12-00494.1

Arora V, Katavouta A, Williams R, Jones C, Brovkin V, Friedlingstein P, Schwinger J, Bopp L, Boucher O, Cadule P, Chamberlain M, Christian J, Delire C, Fisher R, Hajima T, llyina T, Joetzjer E, Kawamiya M, Koven C, Krasting J, Law R, Lawrence D, Lenton A, Lindsay K, Pongratz J, Raddatz T, Séférian R, Tachiiri K, Tjiputra J, Wiltshire A, Wu T, Ziehn T (2020) Carbon-concentration and carbon-climate feedbacks in CMIP6 models, and their comparison to CMIP5 models. Biogeosciences. in press

Danabasoglu G, Gent PR (2009) Equilibrium climate sensitivity: is it accurate to use a slab ocean model? J Clim 22:2494-2499. https://doi.org/10.1175/ 2008JCLI2596.1
Eby M, Zickfeld K, Montenegro A, Archer D, Meissner KJ, Weaver AJ (2009) Lifetime of anthropogenic climate change: millennial time scales of potential CO2 and surface temperature perturbations. J Clim 22:2501-2511. https://doi. org/10.1175/2008JCLI2554.1

Eby M, Weaver AJ, Alexander K, Zickfeld K, Abe-Ouchi A, Cimatoribus AA, Crespin E, Drijfhout SS, Edwards NR, Eliseev AV, Feulner G, Fichefet T, Forest CE, Goosse H, Holden PB, Joos F, Kawamiya M, Kicklighter D, Kienert H, Matsumoto K, Mokhov II, Monier E, Olsen SM, Pedersen JOP, Perrette M, Philippon-Berthier G, Ridgwell A, Schlosser A, Von Deimling TS, Shaffer G, Smith RS, Spahni R, Sokolov AP, Steinacher M, Tachiiri K, Tokos K, Yoshimori M, Zeng N, Zhao F (2013) Historical and idealized climate model experiments: an intercomparison of Earth system models of intermediate complexity. Clim Past 9:1111-1140. https://doi.org/10.5194/cp-9-1111-2013

Ehlert D, Zickfeld K (2017) What determines the warming commitment after take back cessation of CO2 emissions? Environ Res Lett 12:015002. https://doi.org/ 10.1088/1748-9326/aa564a

Eyring V, Bony S, Meehl GA, Senior CA, Stevens B, Stouffer RJ, Taylor KE (2016) Overview of the Coupled Model Intercomparison Project Phase 6 (CMIP6) experimental design and organization. Geosci Model Dev 9:1937-1958. https://doi.org/10.5194/gmd-9-1937-2016

Frölicher TL, Winton M, Sarmiento JL (2013) Continued global warming after $\mathrm{CO}_{2}$ emissions stoppage. Nat Clim Chang 3:1-5. https://doi.org/10.1038/ nclimate 2060

Frölicher TL, Sarmiento JL, Paynter DJ, Dunne JP, Krasting JP, Winton M (2015) Dominance of the Southern Ocean in anthropogenic carbon and heat uptake in CMIP5 models. J Clim 28:862-886. https://doi.org/10.1175/JCLI-D14-00117.1

Gillett NP, Arora VK, Matthews D, Allen MR (2013) Constraining the ratio of global warming to cumulative $\mathrm{CO}_{2}$ emissions using CMIP5 simulations. J Clim 26: 6844-6858. https://doi.org/10.1175/JCLI-D-12-00476.1

Goodwin P, Williams RG, Ridgwell A (2015) Sensitivity of climate to cumulative carbon emissions due to compensation of ocean heat and carbon uptake. Nat Geosci 8:29-34. https://doi.org/10.1038/ngeo2304

Gregory JM, Ingram WJ, Palmer MA, Jones GS, Stott PA, Thorpe RB, Lowe JA, Johns TC, Williams KD (2004) A new method for diagnosing radiative forcing and climate sensitivity. Geophys Res Lett 31:2-5. https://doi.org/10.1029/ 2003GL018747

Gruber N, Clement D, Carter BR, Feely RA, Van Heuven S, Hoppema M, Ishii M, Key RM, Kozyr A, Lauvset S, Le Monaco C, Mathis JT, Murata A, Olsen A, Perez FF, Abine CL, Tanhua T, Wanninkhof R (2019) The oceanic sink for anthropogenic $\mathrm{CO}_{2}$ from 1994 to 2007. Science 363:1193-1199

Hajima T, Ise T, Tachiiri K, Kato E, Watanabe S, Kawamiya M (2012) Climate change, allowable emission, and earth system response to representative concentration pathway scenarios. J Meteorol Soc Japan 90:417-434. https:// doi.org/10.2151/jmsj.2012-305

Hajima T, Kawamiya M, Watanabe M, Kato E, Tachiiri K, Sugiyama M, Watanabe S, Okajima H, Ito A (2014) Modeling in Earth system science up to and beyond IPCC AR5. Prog Earth Planet Sci 1:29. https://doi.org/10.1186/s40645-0140029-y

Hajima T, Watanabe M, Yamamoto A, Tatebe H, Noguchi A, Abe M, Ohgaito R, Ito A, Yamazaki D, Ito A, Takata K, Ogochi K, Watanabe S (2020) Development of the MIROC-ES2L Earth system model and the evaluation of biogeochemical processes and feedbacks. Geosci Model Dev 13:2197-2244 https://doi.org/10. 5194/gmd-13-2197-2020

Ito T, Follows MJ (2005) Preformed phosphate, soft tissue pump and atmospheric CO2. J Mar Res 63:813-839. https://doi.org/10.1357/0022240054663231

Ito A, Inatomi M (2012) Water-use efficiency of the terrestrial biosphere: a model analysis focusing on interactions between the global carbon and water cycles. J Hydrometeorol 13:681-694. https://doi.org/10.1175/JHM-D10-05034.1

Iudicone D, Rodgers KB, Plancherel Y, Aumont O, Ito T, Key RM, Madec G, Ishii M (2016) The formation of the ocean's anthropogenic carbon reservoir. Sci Rep 6:1-16. https://doi.org/10.1038/srep35473

Jones DC, Ito T, Takano Y, Hsu WC (2014) Spatial and seasonal variability of the air-sea equilibration timescale of carbon dioxide. Glob Biogeochem Cycles 28:1163-1178. https://doi.org/10.1002/2014GB004813

Jones CD, Arora V, Friedlingstein P, Bopp L, Brovkin V, Dunne J, Graven H, Hoffman F, llyina T, John JG, Jung M, Kawamiya M, Koven C, Pongratz J, Raddatz T, Randerson J, Zaehle S (2016) The C4MIP experimental protocol for CMIP6. Geosci Model Dev 9:2853-2880. https://doi.org/10.5194/gmd-9-28532016 
Jones CD, Frölicher TL, Koven C, MacDougall AH, Damon Matthews H, Zickfeld K, Rogelj J, Tokarska KB, Gillett NP, llyina T, Meinshausen M, Mengis N, Séférian R, Eby M, Burger FA (2019) The Zero Emissions Commitment Model Intercomparison Project (ZECMIP) contribution to C4MIP: quantifying committed climate changes following zero carbon emissions. Geosci Model Dev 12:4375-4385. https://doi.org/10.5194/gmd-12-4375-2019

Joos F, Roth R, Fuglestvedt JS, Peters GP, Enting IG, Von Bloh W, Brovkin V, Burke EJ, Eby M, Edwards NR, Friedrich T, Frölicher TL, Halloran PR, Holden PB, Jones C, Kleinen T, Mackenzie FT, Matsumoto K, Meinshausen M, Plattner GK, Reisinger A, Segschneider J, Shaffer G, Steinacher M, Strassmann K, Tanaka K, Timmermann A, Weaver AJ (2013) Carbon dioxide and climate impulse response functions for the computation of greenhouse gas metrics: a multimodel analysis. Atmos Chem Phys 13:2793-2825. https://doi.org/10.5194/acp13-2793-2013

Kawamiya M, Hajima T, Kaoru T, Watanabe S, Yokohata T (2020) Two decades of Earth system modeling with an emphasis on Model for Interdisciplinary Research on Climate (MIROC). in review.

Li C, von Storch JS, Marotzke J (2013) Deep-ocean heat uptake and equilibrium climate response. Clim Dyn 40:1071-1086. https://doi.org/10.1007/s00382012-1350-z

MacDougall AH (2017) The oceanic origin of path- independent carbon budgets. Sci Rep 7:10373. https://doi.org/10.1038/s41598-017-10557-x

MacDougall AH, Frölicher TL, Jones CD, Rogelj J, Matthews HD, Zickfeld K, Arora VK, Barrett NJ, Brovkin V, Burger FA, Eby M, Eliseev AV, Hajima T, Holden PB, Jeltsch-Thömmes A, Koven C, Menviel L, Michou M, Mokhov II, Oka A, Schwinger J, Séférian R, Shaffer G, Sokolov A, Tachiiri K, Tjiputra J, Wiltshire A, Ziehn T (2020) Is there warming in the pipeline? A multi-model analysis of the zero emission commitment from CO2. Biogeosci. 17:2987-3016 https:// doi.org/10.5194/bg-17-2987-2020

Matthews HD, Gillett NP, Stott PA, Zickfeld K (2009) The proportionality of global warming to cumulative carbon emissions. Nature 459:829-832. https://doi. org/10.1038/nature08047

Mauritsen T, Bader J, Becker T, Behrens J, Crueger T, Esch M, Fast I, Fiedler S, Fläschner D, Hagemann S, Hedemann C, Hohenegger C, llyina T (2019) Developments in the MPI-M Earth System Model version. J Adv Model Earth Syst 11:998-1038. https://doi.org/10.1029/2018MS001400

Obase T, Abe-Ouchi A, Kusahara K, Hasumi H, Ohgaito R (2017) Responses of basal melting of Antarctic ice shelves to the climatic forcing of the last glacial maximum and $\mathrm{CO}_{2}$ doubling. J Clim 30:3473-3497. https://doi.org/10. 1175/JCLI-D-15-0908.1

Paynter D, Frölicher TL, Horowitz LW, Silvers LG (2018) Equilibrium climate sensitivity obtained from multimillennial runs of two GFDL climate models. J Geophys Res Atmos 123:1921-1941. https://doi.org/10.1002/2017JD027885

Rogelj J, Shindell D, Jiang K, Fifita S, Forster P, Ginzburg V, Handa C, Kheshgi H, Kobayashi S, Kriegler E, Mundaca L, Séférian R, Vilariño MV (2018) Mitigation pathways compatible with $1.5^{\circ} \mathrm{C}$ in the context of sustainable development. In: Global warming of $1.5^{\circ} \mathrm{C}$, an IPCC Special Report on the impacts of global warming of $1.5^{\circ} \mathrm{C}$ above pre-industrial levels and related global greenhouse gas emission pathways, in the context of strengthening the global response to the threat of climate change, sustainable development, and efforts to eradicate poverty. World Meteorological Organization.

Rugenstein M, Bloch-Johnson J, Abe-Ouchi A, Andrews T, Beyerle U, Cao L, Chadha T, Danabasoglu G, Dufresne J-L, Duan L, Foujols M-A, Frölicher T, Geoffroy O, Gregory J, Knutti R, Li C, Marzocchi A, Mauritsen T, Menary M, Moyer E, Nazarenko L, Paynter D, Saint-Martin D, Schmidt GA, Yamamoto A Yang S (2019) LongRunMIP - motivation and design for a large collection of millennial-length AO-GCM simulations. Bull Am Meteorol Soc 100:2551-2570. https://doi.org/10.1175/bams-d-19-0068.1

Sabine CL, Feely RA, Gruber N, Key RM, Lee K, Bullister JL, Wanninkhof R, Wong CS, Wallace DWR, Tilbrook B, Millero FJ, Peng TH, Kozyr A, Ono T, Rios AF (2004) The oceanic sink for anthropogenic $\mathrm{CO}_{2}$. Science 305:367-371. https:// doi.org/10.1126/science.1097403

Saint-Martin D, Geoffroy O, Watson L, Douville H, Bellon G, Voldoire A, Cattiaux J, Decharme B, Ribes A (2019) Fast-forward to perturbed equilibrium climate. Geophys Res Lett 46:8969-8975. https://doi.org/10.1029/2019GL083031

Sato H, Itoh A, Kohyama T (2007) SEIB-DGVM: a new dynamic global vegetation model using a spatially explicit individual-based approach. Ecol Model 200: 279-307. https://doi.org/10.1016/j.ecolmodel.2006.09.006

Schwinger J, Tijiputra J (2018) Ocean carbon cycle feedbacks under negative emissions. Geophys Res Lett 45:5062-5070. https://doi.org/10.1029/ 2018GL077790
Seshadri AK (2017) Origin of path independence between cumulative $\mathrm{CO}_{2}$ emissions and global warming. Clim Dyn 49:3383-3401. https://doi.org/10. 1007/s00382-016-3519-3

Stocker TF, Dahe Q, Plattner G-K, Alexander L V., Allen SK, Bindoff NL, Bréon F-M, Church JA, Cubasch U, Emori S, Forster P, Friedlingstein P, Gillett N, Gregory JM, Hartmann DL, Jansen E, Kirtman B, Knutti R, Kanikicharla KK, Lemke P, Marotzke J, Masson-Delmotte V, Meehl GA, Mokhov II, Piao S, Ramaswamy V, Randall D, Rhein M, Rojas M, Sabine C, Shindell D, Talley LD, Vaughan DG, Xie S-P (2013) Technical summary. In: Climate change 2013: the physical science basis. Contribution of Working Group I to the Fifth Assessment Report of the Intergovernmental Panel on Climate Change. Cambridge University Press, Cambridge, United Kingdom and New York, NY, USA.

Tachiiri K, Hajima T, Kawamiya M (2019) Increase of the transient climate response to cumulative carbon emissions with decreasing $\mathrm{CO}_{2}$ concentration scenarios. Environ Res Lett 14:124067. https://doi.org/10.1088/1748-9326/ ab57d3

Taylor KE, Stouffer RJ, Meehl GA (2012) An overview of CMIP5 and the experiment design. Bull Am Meteorol Soc 93:485-498. https://doi.org/10. 1175/BAMS-D-11-00094.1

Tsutsui J (2020) Diagnosing transient response to CO2 forcing in coupled atmosphere-ocean model experiments using a climate model emulator. Geophys Res Lett 47:e2019GL085844 https://doi.org/10.1029/2019GL085844

United Nations (1992) United Nations Framework Convention on Climate Change. United Nations.

United Nations (2015) Paris agreement: twenty-first conference of the parties of the United Nations Framework Convention on Climate Change. United Nations.

Watanabe S, Hajima T, Sudo K, Nagashima T, Takemura T, Okajima H, Nozawa T, Kawase H, Abe M, Yokohata T, Ise T, Sato H, Kato E, Takata K, Emori S, Kawamiya M (2011) MIROC-ESM 2010: Model description and basic results of CMIP5-20c3m experiments. Geosci Model Dev 4:845-872. https://doi.org/10. 5194/gmd-4-845-2011

Williams RG, Goodwin P, Roussenov VM, Bopp L (2016) A framework to understand the transient climate response to emissions. Environ Res Lett 11: 015003. https://doi.org/10.1088/1748-9326/11/1/015003

Yamamoto A, Shigemitsu M, Oka A, Takahashi K, Ohgaito R, Yamanaka Y (2015) Global deep ocean oxygenation by enhanced ventilation in the Southern Ocean under long-term global warming. Glob Biogeochem Cycles 29:18011815. https://doi.org/10.1002/2015GB005181

Yamamoto A, Abe-Ouchi A, Yamanaka Y (2018) Long-term response of oceanic carbon uptake to global warming via physical and biological pumps. Biogeosciences 15:4163-4180. https://doi.org/10.5194/bg-15-4163-2018

Zickfeld K, Eby M, Weaver AJ, Alexander K, Crespin E, Edwards NR, Eliseev AV, Feulner $G$, Fichefet $T$, Forest $C E$, Friedlingstein $P$, Goosse $H$, Holden PB, Joos F, Kawamiya M, Kicklighter D, Kienert H, Matsumoto K, Mokhov II, Monier E, Olsen SM, Pedersen JOP, Perrette M, Philippon-Berthier G, Ridgwell A, Schlosser A, Von Deimling TS, Shaffer G, Sokolov A, Spahni R, Steinacher M, Tachiiri K, Tokos KS, Yoshimori M, Zeng N, Zhao F (2013) Long-term climate change commitment and reversibility: an EMIC intercomparison. J Clim 26: 5782-5809. https://doi.org/10.1175/JCLI-D-12-00584.1

\section{Publisher's Note}

Springer Nature remains neutral with regard to jurisdictional claims in published maps and institutional affiliations. 